\title{
Quality Assessment of Surface Current Fields From TerraSAR-X and TanDEM-X Along-Track Interferometry and Doppler Centroid Analysis
}

\author{
Roland Romeiser ${ }^{1}$, Member, IEEE, \\ Hartmut Runge $^{2}$, Steffen Suchandt ${ }^{2}$, Ralph Kahle ${ }^{3}$, Cristian Rossi ${ }^{2}$, \\ and Paul S. Bell ${ }^{4}$ \\ ${ }^{1}$ University of Miami, Rosenstiel School of Marine and Atmospheric Science (RSMAS) \\ 4600 Rickenbacker Causeway, Miami, FL 33149, USA \\ Phone: +1 305421 4645, Fax: +1 305421 4701, E-Mail: rromeiser@rsmas.miami.edu \\ ${ }^{2}$ German Aerospace Center (DLR), Remote Sensing Technology Institute \\ 82234 Wessling, Germany \\ ${ }^{3}$ German Aerospace Center (DLR), German Space Operations Center \\ 82234 Wessling, Germany \\ ${ }^{4}$ National Oceanography Centre \\ Liverpool L3 5DA, UK \\ Revised Version \\ submitted to \\ IEEE Transactions on Geoscience and Remote Sensing
}

May 21, 2013 


\begin{abstract}
All existing examples of current measurements by spaceborne synthetic aperture radar (SAR) along-track interferometry (ATI) have suffered from short baselines and corresponding low sensitivities. Theoretically, the best data quality at $\mathrm{X}$ band is expected at effective baselines on the order of $30 \mathrm{~m}$, i.e. 30 times as long as the baselines of the divided-antenna modes of TerraSAR-X. In early 2012, we had a first opportunity to obtain data at near-optimum baselines from the TanDEM-X satellite formation. In this paper we analyze two TanDEM-X interferograms acquired over the Pentland Firth (Scotland) with effective alongtrack baselines of $25 \mathrm{~m}$ and $40 \mathrm{~m}$. For comparison we consider a TerraSAR-X Dual Receive Antenna mode interferogram with an effective baseline of $1.15 \mathrm{~m}$, as well as velocity fields obtained from Doppler centroid analysis (DCA) of single-antenna data from the same scenes. We show that currents derived from the TanDEM-X interferograms have a residual noise level of $0.1 \mathrm{~m} / \mathrm{s}$ at an effective resolution of about $33 \mathrm{~m} \times 33 \mathrm{~m}$, while DRA-mode data must be averaged over $1000 \mathrm{~m} \times 1000 \mathrm{~m}$ to reach the same level of accuracy. A comparison with reference currents from a $1 \mathrm{~km}$-resolution tide computation system shows good agreement in all three cases. The DCA-based currents are found to be less accurate than the ATIbased ones, but close to short-baseline ATI results in quality. We conclude that DCA is a considerable alternative to divided-antenna mode ATI, while our TanDEM-X results demonstrate the true potential of the ATI technique at near-optimum baselines.
\end{abstract}

\title{
KEYWORDS
}

Synthetic aperture radar, Interferometry, Radar velocity measurement, Remote sensing. 


\section{INTRODUCTION}

A little more than 25 years ago, Goldstein \& Zebker described the concept of ocean surface current measurements by synthetic aperture radar (SAR) along-track interferometry (ATI) and presented a first example result [1]. Since then, the feasibility of current measurements by this technique has been demonstrated in a number of further experiments, using interferometric SAR (InSAR) systems on aircraft (e.g. [2-5]), on a space shuttle [6,7], and on the first ATI-capable satellite, the German TerraSAR-X [8]. Furthermore, some theoretical studies have been performed to understand the ATI imaging mechanism of current and wave fields and to find out how the ATI data quality depends on radar frequency, incidence angle, alongtrack (AT) baseline, etc., and what parameter combinations are most promising for accurate highresolution current measurements (e.g. $[9,10])$. According to these studies, optimal AT baselines, defining the time lag between the two SAR images that form an interferogram, should be on the order of 20-30 m for satellite-based X band ATI systems. Here we always refer to the "effective" AT baseline, which is half the physical AT distance between the two antennas if only one of them is used for transmitting and both for receiving, as it is the case with the TerraSAR-X and TanDEM-X data considered in this work.

Unfortunately, the Shuttle Radar Topography Mission setup (used in [6,7]) and the divided-antenna modes of TerraSAR-X (explained in [10-12] and used in [8]) have offered effective AT baselines of only $3.5 \mathrm{~m}$ and approx. $1 \mathrm{~m}$, respectively, resulting in a clearly suboptimal sensitivity to target velocities and the requirement to average the interferograms over thousands of full-resolution pixels to reduce phase noise. This degrades the effective spatial resolution to several $100 \mathrm{~m}$ at best. In contrast to this, the AT baselines between the TerraSAR-X satellite (launched in June 2007) and its companion TanDEM-X (launched in June 2010) are too long over most ocean regions of interest: With the standard helical orbit pattern, the two satellites have an AT distance between 0 at the northern- and southernmost points of the orbit and about $550 \mathrm{~m}$ over the equator [13], limiting the region of useful baselines for inter-satellite interferometry over water to narrow latitude bands far in the north and south. In regions of longer AT baselines, the data quality suffers from temporal decorrelation of the backscattered signal.

However, the TanDEM-X formation geometry gets modified from time to time to optimize the cross-track interferometry (XTI) performance in certain regions or for certain applications. A setup used from January 12 through March 29, 2012, shifted the region of useful AT baselines to a latitude band that included the area around the Orkney Islands off the northern coast of Scotland [13]. The strait between the Scottish mainland and the Orkney Islands, the so-called Pentland Firth, is a very good test site for current meas- 
urements, since the tidal currents at some locations can get as large as $5 \mathrm{~m} / \mathrm{s}$, which makes them attractive for renewable energy projects. Because of this, the flow conditions are relatively well known, and it is relatively easy to obtain reference data from in-situ measurements and numerical circulation models for an evaluation of the ATI data quality. Furthermore, we already acquired ATI data in this area in the two divided-antenna modes of TerraSAR-X, the Aperture Switching (AS) and Dual Receive Antenna (DRA) modes, in 2009 and 2010, such that a return to the Pentland Firth was a natural preferred choice for longer-baseline ATI tests.

In the following, we analyze two interferometric TanDEM-X datasets acquired at the Pentland Firth on February 26 and March 19, 2012, and the data quality improvements with respect to a TerraSAR-X DRAmode dataset from April 26, 2010. In addition to the interferometry results, we consider current fields from a Doppler centroid analysis (DCA) of single-antenna data from all three cases. As reference we use current fields from the numerical offshore tide computation system POLPRED. The available radar datasets and the processing steps for deriving line-of-sight surface current fields from the interferometric data are described in detail in the following section. In Section III we compare the ATI-based line-of-sight current fields with corresponding POLPRED results. Section IV deals with the DCA technique and a comparison of DCA and ATI results. Final conclusions and an outlook are presented in Section V.

\section{Available Data And Processing Steps}

Fig. 1 shows the location of the Orkney Islands and the Pentland Firth north of the mainland of Scotland. After a few experimental AS-mode data acquisitions over this area in late 2009, with very narrow swath widths on the order of $5 \mathrm{~km}$, a first TerraSAR-X ATI dataset of the Pentland Firth with the full swath width of $30 \mathrm{~km}$ was acquired in DRA mode on April 26, 2010, at 06:41 UTC (corresponding to 7:41 local time / British Summer Time at this time of the year). Almost exactly the same area is covered by the two TanDEM-X datasets from February 26 and March 19, 2012, again at 06:41 UTC (now equal to local time). All three scenes have a nominal incidence angle of $31^{\circ}$ and a full-resolution pixel spacing on the order of $1.7 \mathrm{~m} \times 2.1 \mathrm{~m}$ (range $\times$ azimuth). Some further acquisition parameters as well as wind speeds and directions at the times of the three satellite overpasses are provided in Table 1. The wind information was taken from weather station data available at http://www.wunderground.com. The nearest weather station is the one at the airport of Kirkwall, the capital of Orkney, approx. $30 \mathrm{~km} \mathrm{NNE}$ of the center of our test area. 


\section{A. TerraSAR-X DRA Mode Data}

The TerraSAR-X DRA-mode dataset was acquired during a specific DRA-mode campaign in spring 2010. While the AS mode uses a single receiver chain for both antenna halves in an alternating manner, the DRA mode uses the main and backup receiver chains of the SAR system in parallel, such that the regular pulse repetition frequency (PRF) can be used and each antenna half receives an image with the full stripmap swath width of $30 \mathrm{~km}$ [10]. The effective AT baseline in DRA mode is approx. $1.15 \mathrm{~m}$. Unfortunately, our dataset was acquired in horizontal $(\mathrm{HH})$ polarization. We prefer vertical (VV) polarization for ATI over water, because of a stronger backscattered signal and a corresponding better signal-to-noise ratio [9].

The basic SAR processing and interferogram generation was performed at the SAR department of the Institute for Remote Sensing Technology, German Aerospace Center (DLR), in Oberpfaffenhofen, Germany, using the optimized procedures described in [14]. The further analysis was done at the University of Miami, Florida, USA. As a first step, the complex pixel values of the interferogram were averaged over grid cells of approx. $25 \mathrm{~m} \times 25 \mathrm{~m}$, corresponding to $15 \times 12=180$ original pixels per grid cell. At the same time, the magnitudes of the complex pixel values (interferogram amplitudes, i.e. products of two complex image amplitudes, dimensionally equivalent to image intensities) were averaged to obtain a reduced-resolution intensity image, and by combining the results of both averaging procedures, the coherence could be computed for each grid cell. In the next step, the phases of the resolution-reduced interferogram were converted into horizontal line-of-sight Doppler velocities, and a large-scale trend in azimuth direction was removed by fitting a quadratic correction function. Results are shown in Fig. 2. Note that the data are presented in image coordinates, i.e. the radar look direction is exactly from right to left in the figures. The detected Doppler velocities and all line-of-sight currents discussed in the following are aligned with this direction, with positive values indicating a motion from left to right.

At this spatial resolution, the Doppler velocities from DRA-mode data are still very noisy, and further averaging is mandatory to obtain meaningful current estimates. The reader may be surprised to see so much phase noise in data with a quite good coherence (mean coherence over water within the black frame = 0.81). The explanation lies in the fact that at such a short baseline, the shown horizontal Doppler velocity interval of $10 \mathrm{~m} / \mathrm{s}$ corresponds to an ATI phase interval of the order of only $\pi / 10$, or $18^{\circ}$ (see column "Velocity Range" in Table 1). Accordingly, the complex numbers in the original interferogram fluctuate around a relatively narrow phase range, which corresponds to high coherence. However, the fluctuations are dominated by instrument noise and not by contributions of actual target velocity variations. This 
makes the Doppler velocities look noisy without further smoothing. As discussed in [10], the TerraSAR-X instrument has a relatively high instrument noise level, which has particularly negative effects on the ATI data quality at the extremely short baselines of the AS and DRA modes.

\section{B. TanDEM-X Data}

As discussed in [13], the TerraSAR-X / TanDEM-X orbit geometry used from January 12 through March 29, 2012, was suitable for current measurements at near-optimum AT baselines in the Orkney region. We were able to program two data acquisitions within the framework of a TanDEM-X science project, including some specific fine tuning of the satellite orbits to optimize the baselines. The resulting effective AT baselines were about 25 and $40 \mathrm{~m}$, respectively, mapping horizontal velocity ranges of $9.14 \mathrm{~m} / \mathrm{s}$ and $5.69 \mathrm{~m} / \mathrm{s}$ into a phase range of $2 \pi$ (see Table 1). At the same time, effective XT baselines on the order of 23-24 m caused mapping of a surface elevation range of about 200-210 m into the same phase interval. Since the actual height variations within the sea surface are two orders of magnitude smaller than this, the topographic contributions to the detected phase variations will be neglected in our interferogram analyses. However, the XT baseline causes a mean phase offset depending on the height of the sea surface with respect to a reference plane. This must be taken into account in the absolute calibration of derived velocities. Unlike our DRA-mode example, the TanDEM-X data were acquired at VV polarization.

Again, the basic SAR processing and interferogram generation for the two TanDEM-X cases was done at DLR, while all further processing and analysis was done at the University of Miami. Because of the unknown phase offset due to the XT baseline, we added an absolute calibration step in which the mean Doppler velocity and current at coastlines perpendicular to the radar look direction were forced to be 0 . The same method was used to adjust the SRTM-derived current fields in [6] and [7], which suffered from exactly the same problem. To eliminate the effect of calibration issues from our comparison of different radar results with each other as well as with model results, we applied the same adjustment to the DRAmode results of Fig. 2, and we adjusted the mean values of the DCA-based Doppler velocities and currents in Section IV such that they match the mean values of the corresponding ATI results (the DCA data do not include suitable coastlines for a calibration based on the coastline current criterion).

Fig. 3 shows interferogram amplitudes, coherences, and Doppler velocities obtained after averaging over $25 \mathrm{~m} \times 25 \mathrm{~m}$ grid cells. In contrast to the DRA-mode data of Fig. 2, the TanDEM-X data show very clear signatures of surface currents at this resolution, despite lower mean coherence levels of 0.72 in the February 26 case and 0.68 in the March 19 case. The coherence decreases with an increasing AT baseline be- 
cause of temporal decorrelation of the backscattered signal. But at the same time, the phase contributions due to target velocities get larger while the instrument-related phase noise stays constant, such that the signal-to-instrument-noise ratio improves. Together, the quality of the velocity measurement is much better at the near-optimum TanDEM-X baselines than at the short DRA-mode baseline because the better signal-to-instrument-noise ratio outweighs the negative effects of signal decorrelation. However, the coherence continues to decrease with further increasing AT baselines, making the data unsuitable for interferometry when it gets too low. Low coherence can also occur where the backscattered power from the sea surface gets close to or below the instrument noise level, such as in the area near the coast at the bottom of Figs. 3a-c that exhibits a low image intensity and coherence and very noisy Doppler velocities.

Another issue at long baselines is phase wrapping. When the range of target velocities in a test area gets larger than the range of velocities mapped into a phase interval of $2 \pi$, some phases wrap around the $\pm \pi$ point, such that large positive velocities appear as negative ones and vice versa. To correct this, one must identify the affected grid points and add or subtract the velocity of ambiguity, extending the total velocity range beyond the range mapped into $[-\pi,+\pi]$. We have a case of phase wrapping in the center of the TanDEM-X scene from March 19, 2012, where the horizontal velocity in the center area is larger than the limit of $2.85 \mathrm{~m} / \mathrm{s}$. This area shows up in blue instead of red color in Fig. $3 \mathrm{f}$. Thanks to the smoothness of the true velocity field, it is easy to detect the boundaries of the phase-wrapped area and to correct the problem.

\section{Initial Data Quality Analysis}

A closer look at Figs. 3c and f suggests that the Doppler velocities exhibit wave patterns that are correlated with the ones visible in the interferogram amplitude images of Figs. 3a and d. Fig. 4 shows this in more detail for a magnified subsection of Figs. 3a and c. For this purpose, the interferogram averaging was done over $5 \times 4$ original pixels only, resulting in a grid cell size of $8.40 \mathrm{~m} \times 8.46 \mathrm{~m}$. Indeed there are clear and consistent wave patterns in the interferogram amplitude and phase signatures. The dominant waves have wavelengths on the order of $200 \mathrm{~m}$. This demonstrates the high quality of the TanDEM-X data at the baselines used here. A detailed analysis of the wave signatures goes beyond the scope of this paper, but we will continue to work on it and present results on another occasion.

A quantitative comparison of the quality of the DRA-mode and TanDEM-X data can be done by analyzing residual Doppler velocity fluctuations as function of the number of averaged samples. We have done this for two homogeneous $4096 \times 4096$ pixel subsections of the full-resolution interferograms from April 26, 2010, and March 19, 2012. Homogeneous means in this context that we selected areas with very small 
spatial current variations, such that the rms variability of phases and Doppler velocities could be attributed to signal decorrelation and instrument noise effects, not to current variations. In both cases, suitable subimages for this purpose were found in the vicinity of the upper right corner of the frames shown in Figs. 2 and 3. We averaged the real and imaginary parts of the complex arrays in groups of $1,2,4,8, \ldots$ up to $1024^{2}$ samples and recomputed the corresponding phases after each step, such that the first step let us compute the rms phase variability of the $4096 \times 4096$ original pixel values, the second step of $2048 \times$ 4096 values averaged over 2 pixels each, the third step of $2048 \times 2048$, and the last step of $4 \times 4=16$ remaining averaged values. Finally, the rms phase variabilities were converted into horizontal Doppler velocity uncertainties. Results are shown in Fig. 5.

We have always assumed that desirable uncertainties of current measurements are on the order of $0.1 \mathrm{~m} / \mathrm{s}$ or less. The curves of Fig. 5 show that the rms variabilities derived from the DRA-mode data and the TanDEM-X data cross this level at approx. 300,000 and 300 samples, respectively. This means one needs to average the full-resolution DRA-mode data over approx. one square kilometer to reduce the residual noise level to $0.1 \mathrm{~m} / \mathrm{s}$, while the TanDEM-X data provide the same accuracy after averaging over only $33 \mathrm{~m} \times 33 \mathrm{~m}$. This is quite impressive, and it confirms that further analysis of the wave patterns in Fig. 4 makes sense. Of course, one always has to take into account that SAR interferograms, like conventional SAR intensity images, are affected by SAR imaging artifacts such as velocity bunching and an azimuth cutoff of resolved wave numbers $[15,16]$. The problem of wave retrievals from ATI imagery was studied theoretically in [17]. Another important comment that must be made in this context is that the quoted accuracy or uncertainty of $0.1 \mathrm{~m} / \mathrm{s}$ is a measure of the remaining statistical noise only. ATI-derived currents will usually have an additional absolute error as a result of calibration uncertainties and suboptimal corrections for wave contributions. These contributions cannot be reduced by averaging.

The results of our data quality analysis are consistent with our simulation-based findings in [10], but in comparing the results for the TerraSAR-X DRA-mode and TanDEM-X data with each other and with theoretical results, one has to take into account that the data were acquired under different wind and wave conditions and at different polarizations. Furthermore, the $4096 \times 4096$ pixel test array taken from the TanDEM-X dataset had visible wave patterns and slight large-scale current variations in it, the latter of which cause the slope of the dashed line in Fig. 5 to decrease at large numbers of samples. This would not happen with data from a perfectly homogeneous area. 


\section{Current Field Filtering and Correction}

Obviously, the DRA-mode velocity field of Fig. 2c needs more spatial averaging to reduce noise, and the TanDEM-X velocity fields of Figs. $3 \mathrm{c}$ and $\mathrm{f}$ should be smoothed across the visible wave patterns to emphasize the underlying current field. In the case of the DRA-mode data, we have done the averaging by applying $11 \times 11$ element boxcar smoothing to the real and imaginary parts of the $25 \mathrm{~m} \times 25 \mathrm{~m}$ grid interferogram three times. Grid points for which the mean coherence in the surrounding $11 \times 11$ element window was smaller than 0.5 were masked out in this procedure, and the resulting gaps were filled by interpolation between the surrounding higher-quality data. Smoothed phases and Doppler velocities were computed from the smoothed and quality-optimized real and imaginary part arrays. The result is shown in Fig. 6a. For the TanDEM-X data we used a similar smoothing method, but with a directional weighting in the $11 \times 11$ element smoothing kernel that accounts for the local dominant wave pattern. This way, the smoothing focuses on the wave pattern while preserving a higher resolution in the direction parallel to the wave crests. Results are shown in Figs. $6 \mathrm{~b}$ and c. Note how the Doppler velocity field obtained for the March 19 case (Fig. 6c) looks clearly smoother than the one obtained for the DRA-mode case (Fig. 6a), which represents a similar tidal scenario. On February 26, 2012, the satellite overpass took place at a tidal phase with an opposite flow direction, which is visible in the current field (Fig. 6b) as well as in the image intensity modulation patterns around the islands (compare Figs. 3a and d).

At this processing level, we have obtained relatively good-looking line-of-sight Doppler velocity arrays. Theoretically, they still include spatially varying contributions of wave motions [9], which should ideally be removed by an iterative modeling procedure as demonstrated in [4]. However, this is difficult to do for such a relatively large test area with complicated current patterns and wind variations around several islands and an unknown current component perpendicular to the radar look direction. Fortunately, experience with the data analysis and numerical simulations in [4-7] has shown that the wave-current interaction effects are usually small. Therefore we limit our corrections to wind-related wave modulation effects, estimating effective surface wind variations from the local current (which affects the relative wind acting on the moving water surface) and from image intensity variations. Corresponding variations of wave contributions to the local Doppler frequency were computed using the model described in [9] and subtracted. All resulting current fields were then recalibrated to satisfy the condition of zero mean currents at coastlines perpendicular to the radar look direction. Figs. 6d-f show our resulting best estimates of the line-ofsight surface current fields in the three cases. The corrections for wind and wave effects tend to enhance the spatial variations in all three velocity fields, but not very much. 


\section{COMPARISON With CirCulation MODEL Results}

Reference current fields for the three satellite overpasses were obtained using the offshore tide computation system POLPRED of the National Oceanography Centre (NOC) in Liverpool, UK. POLPRED uses 26 harmonics derived from the 2D high-resolution numerical circulation model CS3 [18] to estimate current fields at any time (i.e. tidal phase) of interest. With this setup, POLPRED can generate a model current field instantly, but it accounts neither for the specific wind scenario at the time of interest nor for possible differences between depth-averaged currents and surface currents. Furthermore, POLPRED's spatial resolution of $1 \mathrm{~km} \times 1 \mathrm{~km}$ can cause unrealistic results in areas with strong depth variations on short spatial scales and complicated coastlines and islands, and it is not fine enough to validate variations in the TanDEM-X ATI-based current fields on shorter spatial scales. These limitations must be taken into account in the interpretation of differences between POLPRED- and ATI-based line-of-sight currents.

Fig. 7 shows line-of-sight components of the POLPRED current fields for our three test scenarios. At first glance, the agreement with the ATI-based current fields at the bottom of Fig. 6 is quite good. A closer look at the current fields and at the mean difference in each grid cell, shown in Fig. 8, reveals that the ATI-based current field for April 26, 2010 (Fig. 6d) has the strongest currents further east than POLPRED (Fig. 7a) and that the westward POLPRED currents for February 26, 2012 (Fig. 7b) are stronger than the ones obtained from the TanDEM-X data (Fig. 6e). For March 19, 2012 (Figs. 6e and 7c), we find a similar difference pattern as for April 26, 2010, but with less pronounced differences. The fact that positive and negative differences occur at the same locations in these two cases with similar flow conditions suggests that a systematic shortcoming of POLPRED or of our data processing technique will always cause similar difference patterns at this tidal phase. We believe that the differences are partly due to an inaccurate and / or outdated bathymetry used in the numerical circulation model runs on which POLPRED is based. The model bathymetry must be based on various datasets from surveys that took place more than 10 years ago, none of which would have been up to modern multibeam echosounding standards.

Fig. 9 shows scatter diagrams and results of a statistical analysis, which was done for the regions marked by black rectangles in Figs. 6d-f and 7. They represent the regions for which DCA results are available as well, as discussed in Section IV. Like the current different maps of Fig. 8, the statistical analysis was done for mean ATI-based currents in each POLPRED grid cell, such that there were no statistical asymmetries due to different spatial resolutions. We computed the shown correlation and regression coefficients, mean differences, and residual rms differences (i.e. rms differences after subtraction of the mean differences). 
The scatter diagrams and the statistical quantities indicate good general agreement. As could be expected, we find better correlation coefficients $(0.862$ and 0.852 vs. 0.781$)$ and smaller residual rms differences $(0.39$ and $0.49 \mathrm{~m} / \mathrm{s}$ vs. $0.80 \mathrm{~m} / \mathrm{s})$ for the two TanDEM-X based products than for the TerraSAR-X DRAmode product. However, the large residual rms difference in the DRA-mode case must be attributed to the discrepancies between spatial current variations (Fig. 8a): According to the findings of Section IIC, the residual statistical uncertainty of the mean ATI-based currents in each POLPRED grid cell of $1 \mathrm{~km} \times 1 \mathrm{~km}$ shouldn't be much larger than $0.1 \mathrm{~m} / \mathrm{s}$.

While regression coefficients and mean differences are very good in the April 26 and March 19 cases, the values for the February 26 case (regression coefficient $=0.739$, mean difference $=0.31 \mathrm{~m} / \mathrm{s}$ ) and the scatter diagram of Fig. 9b show even more than the current difference map of Fig. $8 b$ that we seem to observe a significantly less pronounced westward flow at the time of this satellite overpass than predicted by POLPRED. To investigate this further, we have compared the TanDEM-X derived current field with POLPRED current fields for different times within an interval of $\pm 60 \mathrm{~min}$ around the nominal time of 6:41 UTC. We find best agreement with the current field for 7:21 UTC (40 minutes after the nominal time of the satellite overpass), where regression coefficient and mean difference improve to 0.999 and $0.04 \mathrm{~m} / \mathrm{s}$, respectively, and the residual $\mathrm{rms}$ difference improves from 0.39 to $0.34 \mathrm{~m} / \mathrm{s}$. Performing the same test for the two other cases for comparison, we find that the differences between ATI-based currents and POLPRED currents are almost constant for about 50 and 30 minutes after the satellite overpasses, respectively. This lets us conclude that the observed surface current fields may be ahead of the POLPRED current fields by approx. 30-40 minutes, possibly as a result of specific wind conditions, seasonal effects, or general shortcomings of the numerical model that was used to derive the spectral parameters of POLPRED. Differences between surface currents and depth-averaged currents are another possible explanation - note that the February 26, 2012, scenario is the only one with a wind component against the current, which may reduce the current close to the surface. However, at this time we do not have sufficient experience with spaceborne ATI-based current fields to rule out shortcomings of our data processing techniques as another potential source of discrepancies. Fig. 10 shows scatter diagrams and statistical quantities for the three ATI-based current fields vs. POLPRED current fields for 7:31, 7:21, and 7:11 UTC, respectively, instead of 6:41 UTC. The spatial distributions of current field differences at these alternate times look still similar to the ones found with the POLPRED current fields for 6:41 UTC (Fig. 8) and are not shown explicitly. 


\section{COMPARISON With DopPler CENTROID ANALysis Results}

Within the last decade, the technique of Doppler centroid analysis (DCA) of single-antenna SAR raw data has been established as a promising alternative to ATI. Following ideas from the late 1970s [19] and a first demonstration with ERS-1 SAR data in 2001 [20], Chapron and coworkers in France and Norway picked up the idea and presented very interesting results in [21] in 2005 and continued to refine their technique and to apply it to a variety of scenarios in the following years (e.g. [22-24]). In contrast to ATI, the DCA technique uses data from a single SAR antenna only, such that it can be applied to a wide range of existing SAR datasets without specific preparations. It exploits differences between Doppler frequencies estimated within the SAR processor and theoretical values based on the imaging geometry and the relative motion between satellite and rotating earth. The Doppler estimation must be performed within a window, thus at a final spatial resolution much lower than the resolution of a fully processed SAR image, but the quality of DCA results has been found to be comparable to the quality of divided-antenna mode ATI results from TerraSAR-X. A qualitative comparison of both techniques was presented in [25].

A demonstration of DCA with TerraSAR-X data was given in [26], but so far, no direct comparison of ATI and DCA results based on the same raw data set has been presented in the literature. Such a comparison is particularly interesting if it can be done with InSAR data acquired at short and near-optimum AT baselines, such as the data considered in this work. Because of this, we decided to apply the techniques of [26] to our three cases and to perform another comparison of the results with the POLPRED current fields, as well as a direct comparison of ATI- and DCA-based Doppler velocity fields. The window used for the spectral estimation is composed of $256 \times 256$ pixels, thus covering about $500 \mathrm{~m}$ in the azimuth direction and $250 \mathrm{~m}$ in range. The estimation is performed every 50 pixels, and the final velocity map is derived using a cubic interpolation and additional smoothing.

Figs. 11a-c show the three Doppler velocity fields obtained from DCA, using the sum signal from the two TerraSAR-X antenna halves in the DRA-mode case and the signal from the master satellite (i.e. the one in monostatic operation) in the two TanDEM-X cases. While this processing could have been done for the complete scenes, it was decided to limit it to the region of strongest currents in the center of the test area, which cause the most significant Doppler variations. As already mentioned, the absolute calibration was forced to match the absolute calibration of the ATI results, i.e. the mean values are the same. Like the SAR raw data processing and interferogram generation, the DCA processing was performed at DLR, while some additional smoothing and the calibration adjustment was done at the University of Miami, as 
well as an application of corrections for wind and wave effects in the same way as it had been done for the ATI data. The resulting current fields are shown in the bottom row of Fig. 11. Differences from the model current fields of Fig. 7 are shown in Fig. 12.

As could be expected, the DCA-based current fields and their differences from the model current fields do not look much different from the ATI results, except for the February 26 case, where the DCA-based current field exhibits significantly stronger currents with much more pronounced spatial variations (compare Figs. 11e and 6e). Scatter diagrams and statistical properties are shown in Fig. 13, using POLPRED current fields for 6:41 UTC in the top row and the ones for 7:31, 7:21, and 7:11 UTC, respectively, in the bottom row, like in Fig. 10. The statistical quantities indicate a somewhat reduced data quality compared to the ATI results. In the February 26 case (center column of Fig. 13), the strong spatial variations in the DCA current field agree better with the POLPRED current field for 6:41 UTC than with the one for 7:21 UTC, but we don't think this justifies the conclusion that something may be wrong with the ATI results, since the spatial variations in the POLPRED current field agree clearly better with the ones in the ATI- than the ones in the DCA-based current field (compare Figs. 8b and 12b). Fig. 14 shows histograms of deviations of the ATI- and DCA-based currents from the POLPRED currents. For all three cases and compared to the POLPRED currents for 6:41 UTC and for the alternate times, the DCA-based currents have a larger percentage of large deviations than the ATI-based ones.

Note that the quality of the DCA current field obtained for the DRA-mode case (left columns of Figs. 11,13) is almost as good as the quality of the corresponding ATI result (left columns of Figs. 6,9). The DCA result for March 19 (right columns of Figs. 11,13) is of even better quality, almost as good as the ATI result obtained with a near-optimum baseline. Of course this is valid at the $1 \mathrm{~km} \times 1 \mathrm{~km}$ grid resolution of POLPRED only, while we demonstrated in Section IIC that the effective spatial resolution of the TanDEM-X ATI-based velocity fields is much higher. The DCA-based current fields cannot match the high resolution of TanDEM-X ATI products due to limitations imposed by the window processing.

Finally, Fig. 15 shows differences between the DCA- and ATI-based Doppler velocity fields of (top rows of Figs. 11 and 6), and Fig. 16 shows corresponding scatter diagrams and statistical quantities. For this analysis, the $25 \mathrm{~m} \times 25 \mathrm{~m}$ grid data were used without further resolution reduction. We find good agreement with correlation coefficients of 0.961 and 0.916 and residual $\mathrm{rms}$ differences of $0.34 \mathrm{~m} / \mathrm{s}$ for the first and the last case, but more pronounced differences and less convincing statistical properties (correlation coefficient $=0.739$, regression coefficient $=1.290$, residual $\mathrm{rms}$ difference $=0.70 \mathrm{~m} / \mathrm{s}$ ) for the February 26 
case. It is not clear what causes this poor agreement, but the comparisons with POLPRED suggest that it can be attributed to anomalies in the DCA-derived current field rather than to a problem with the ATI result. Since the DCA processing was a specifically requested voluntary contribution, we do not have the resources to study the problem in more detail within the framework of this work.

\section{CONCLUSIONS AND OUTLOOK}

For the first time we have been able to test and demonstrate ocean current measurements by spaceborne InSAR at near-optimum AT baselines of about 25 and $40 \mathrm{~m}$, using TanDEM-X data from February 26 and March 19, 2012, when a temporarily available formation geometry permitted such measurements in a latitude band including the northern North Sea and our test site, the Pentland Firth. For comparison, we included a TerraSAR-X Dual Receive Antenna mode (DRA mode) dataset in the analysis, as well as current fields derived from single-antenna data using the DCA technique. Reference current fields were taken from the tidal computation system POLPRED.

We were able to show that the rms variability of TanDEM-X derived velocities at these baselines gets better than $0.1 \mathrm{~m} / \mathrm{s}$ after averaging over just $33 \mathrm{~m} \times 33 \mathrm{~m}(\mathrm{vs}$. about $1000 \mathrm{~m} \times 1000 \mathrm{~m}$ for the short-baseline DRA-mode data), which makes it possible to resolve orbital motions of long surface waves. All ATIbased current fields showed good agreement with corresponding POLPRED current fields, but the results obtained for the February 26, 2012, case suggest that POLPRED may be lagging behind the observed surface currents by approx. 30-40 minutes. In the other two cases, the POLPRED current fields are almost constant for 30-50 minutes after the TerraSAR-X / TanDEM-X overpass time, such that a similar time lag between model and observations may be present on those days. Alternatively, the problem may be related to differences between surface currents and depth-averaged currents or other shortcomings of the model physics, or to suboptimal ATI data processing. This could not be decided within the framework of this work, but we think our results demonstrate the advantages and the potential of ATI at near-optimum baselines quite well despite the open questions.

The DCA-based current fields are less accurate than the ATI-based ones and seem to exhibit unrealistically strong spatial variations in the February 26 case, but the other two DCA results are almost as good as the ATI results when compared with the POLPRED current fields at $1 \mathrm{~km} \times 1 \mathrm{~km}$ resolution. This confirms that DCA is a promising current retrieval technique for cases that do not require the highest possible spatial resolution. Furthermore, together with the finding that the effective spatial resolution of our DRA- 
mode data is not much better than $1 \mathrm{~km} \times 1 \mathrm{~km}$, one can conclude that DCA can deliver current fields of almost the same quality as ATI in the short-baseline DRA and AS modes of TerraSAR-X for many applications. Only in cases that require high spatial resolution in a particular direction, such as current measurements in rivers or over oceanic internal waves, short-baseline ATI will have an advantage over DCA because it permits accurate land masking and nonisotropic smoothing of full-resolution interferograms.

In the coming months, we will analyze the wave signatures in existing ATI data in more detail and check if the coherence of TanDEM-X data at various AT baselines is consistent with theoretical predictions. Furthermore, we will try to acquire additional TanDEM-X data at near-optimum baselines and to obtain higher-resolution model current fields for a more detailed analysis of short-scale spatial variations. There is a good chance that suitable orbit geometries for current measurements will be made available more frequently when the main mission objectives of TanDEM-X have been accomplished, such that many science users can benefit from the high data quality and from the data processing experiences gained from activities such as the ones described in this paper. TanDEM-X may be ready for this in 2014 .

\section{ACKNOWLEDGMENTS}

This work has been funded by the U.S. Office of Naval Research (ONR) under grant N00014-11-1-0280 (SARprises, PI: Roland Romeiser). The TanDEM-X data were obtained through TanDEM-X science project ATI-OCEA0599 (PI: Hartmut Runge). TerraSAR-X and TanDEM-X data (C) German Aerospace Center (DLR). 


\section{REFERENCES}

[1] R.M. Goldstein and H.A. Zebker, "Interferometric radar measurement of ocean surface currents", Nature, vol. 328, pp. 707-709, 1987.

[2] D.R. Thompson and J.R. Jensen, "Synthetic aperture radar interferometry applied to ship-generated waves in the 1989 Loch Linnhe experiment", J. Geophys. Res., vol. 98, pp. 10,259-10,269, 1993.

[3] H.C. Graber, D.R. Thompson, and R.E. Carande, "Ocean surface features and currents measured with synthetic aperture radar interferometry and HF radar", J. Geophys. Res., vol. 101, pp. 25,813-25,832, 1996.

[4] R. Romeiser, "Current measurements by airborne along-track InSAR: Measuring technique and experimental results", IEEE J. Ocean. Eng., vol. 30, pp. 552-569, 2005.

[5] J.V. Toporkov, D. Perkovic, G. Farquharson, M.A. Sletten, and S.J. Frasier, "Sea surface velocity vector retrieval using dual-beam interferometry: First demonstration", IEEE Trans. Geosci. Remote Sensing, vol. 43, pp. 2494-2502, 2005.

[6] R. Romeiser, H. Breit, M. Eineder, H. Runge, P. Flament, K. de Jong, and J. Vogelzang, "Current measurements by SAR along-track interferometry from a space shuttle", IEEE Trans. Geosci. Remote Sensing, vol. 43, pp. 2315-2324, 2005.

[7] R. Romeiser, H. Runge, S. Suchandt, J. Sprenger, H. Weilbeer, A. Sohrmann, and D. Stammer, "Current measurements in rivers by spaceborne along-track InSAR", IEEE Trans. Geosci. Remote Sensing, vol. 45, pp. 4019-4030, 2007.

[8] R. Romeiser, S. Suchandt, H. Runge, U. Steinbrecher, and S. Grünler, "First analysis of TerraSAR-X along-track InSAR-derived current fields", IEEE Trans. Geosci. Remote Sensing, vol. 48, pp. 820-829, 2010.

[9] R. Romeiser and D.R. Thompson, "Numerical study on the along-track interferometric radar imaging mechanism of oceanic surface currents", IEEE Trans. Geosci. Remote Sensing, vol. 38-II, pp. 446-458, 2000.

[10] R. Romeiser and H. Runge, "Theoretical evaluation of several possible along-track InSAR modes of TerraSAR-X for ocean current measurements", IEEE Trans. Geosci. Remote Sensing, vol. 45, pp. 21-35, 2007.

[11] J. Mittermayer, V. Alberga, S. Buckreuß, and S. Riegger, "TerraSAR-X: Predicted performance", in Proc. SPIE 9th Int. Symp. Rem. Sensing, 12 pp., Int. Soc. Optical Eng., Bellingham, WA. USA, 2002.

[12] J. Mittermayer and H. Runge, "Conceptual studies for exploiting the TerraSAR-X dual receive antenna", in Proc. IGARSS 2003, 3 pp., Inst. of Elec. and Electron. Eng., Piscataway, N.J., USA, 2003.

[13] R. Kahle, H. Runge, J.S. Ardaens, S. Suchandt, and R. Romeiser, "Formation flying for along-track interferometric oceanography First in-flight demonstration with TanDEM-X", in Proc. 23rd International Symposium on Space Flight Dynamics, 17 pp., NASA JPL, Pasadena, California, 2012.

[14] S. Suchandt, H. Runge, H. Breit, and U. Steinbrecher, "Automatic extraction of traffic flows and surface currents using TerraSAR-X along-track interferometry", IEEE Trans. Geosci. Remote Sensing, vol. 48, pp. 807-819, 2010.

[15] W. Alpers, D.B. Ross, and C.L. Rufenach, "On the detectability of ocean surface waves by real and synthetic aperture radar", $J$. Geophys. Res., vol. 86, pp. 6481-6498, 1981.

[16] K. Hasselmann, R.K. Raney, W.J. Plant, W. Alpers, R.A. Shuchman, D.R. Lyzenga, C.L. Rufenach, and M.J. Tucker, "Theory of synthetic aperture radar ocean imaging: A MARSEN view", J. Geophys. Res., vol. 90, pp. 4659-4686, 1985.

[17] M. Bao, C. Bruening, and W. Alpers, "Simulation of ocean waves imaging by an along-track interferometric synthetic aperture radar", IEEE Trans. Geosci. Remote Sensing, vol. 35, pp. 618-631, 1997.

[18] R.A. Flather, "Existing operational oceanography", Coastal Engineering, vol. 41 (1-3) , pp. 13-40, 2000.

[19] R. Shuchman, "The feasibility of measurement of ocean current detection using SAR data", in Proc. 13th Int. Symp. Remote Sensing of Environment, pp. 93-103, Ann Arbor, MI, USA, 1979. 
[20] M. van der Kooij, W. Hughes, and S. Sato, "Doppler current velocity measurements: A new dimension to spaceborne SAR data", report published online by Atlantis Scientific, Ontario, Canada, 2001.

[21] B. Chapron, F. Collard, and F. Ardhuin, "Direct measurements of ocean surface velocity from space: Interpretation and validation", J. Geophys. Res., vol. 110, C07008, 17 pp., 2005.

[22] J.A. Johannessen, F. Collard, V.N. Kudryavtsev, and D.D. Akimov, "Direct ocean surface velocity measurements from space: Improved quantitative interpretation of Envisat ASAR observations", Geophys. Res. Letters, vol. 35, L22608, 6 pp., 2008.

[23] M.J. Rouault, A. Mouche, F. Collard, J.A. Johannessen, and B. Chapron, "Mapping the Agulhas Current from space: An assessment of ASAR surface current velocities", J. Geophys. Res., vol. 115, C10026, 14 pp., 2010.

[24] M.W. Hansen, J.A. Johannessen, K.F. Dagestad, F. Collard, and B. Chapron, "Monitoring the surface inflow of Atlantic Water to the Norwegian Sea using Envisat ASAR", J. Geophys. Res., vol. 116, C12008, 13 pp., 2011.

[25] R. Romeiser, J. Johannessen, B. Chapron, F. Collard, V. Kudryavtsev, H. Runge, and S. Suchandt, "Direct surface current field imaging from space by along-track InSAR and conventional SAR", in Oceanography From Space, Revisited, V. Barale, J.F.R. Gower, and L. Alberotanza (eds.), pp. 73-91, Springer Science+Business Media, 2010.

[26] C. Rossi, H. Runge, H. Breit, and T. Fritz, "Surface current retrieval from TerraSAR-X data using Doppler measurements", in Proc. IGARSS 2010, 4 pp., IEEE, 2010. 


\section{BIOGRAPHY}

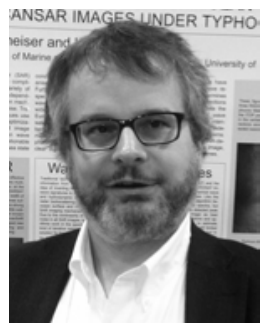

Roland Romeiser (M'00) received the Dipl.-Phys.degree from the University of Bremen, Germany, in 1990 and the Dr.rer.nat. and Habilitation degrees from the University of Hamburg, Germany, in 1993 and 2007, respectively. He was a Project Scientist with the Institute of Oceanography, University of Hamburg, from 1990 to 1998 and a permanent Staff Scientist with the same institute from 1999 to 2009. From August 1998 to July 1999, he spent a year with the Applied Physics Laboratory, Johns Hopkins University, Laurel, MD, as a Feodor Lynen Fellow of the Alexander von Humboldt Foundation. Since April 2008 he has been an Associate Professor with the Rosenstiel School of Marine and Atmospheric Science of the University of Miami, FL. Dr. Romeiser has wide experience in the field of remote sensing of ocean currents, waves, and winds by airborne and spaceborne microwave radars. He has been involved in many international remote sensing projects and experiments in this field and authored and coauthored 24 peer-reviewed journal articles and 65 conference articles and book contributions and organized and chaired several sessions at international remote sensing conferences. Since fall 2000 he is an Associate Editor of the IEEE JOURNAL OF OCEANIC ENGINEERING. His research interests focus on the theoretical modeling of microwave radar signatures of ocean features and on the development and evaluation of new and improved techniques for current and wave measurements by conventional and interferometric synthetic aperture radar.

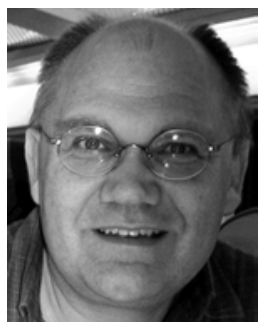

Hartmut Runge (56) received the Dipl.-Ing. degree in electrical engineering / communications from the University of Siegen, Germany, in 1980. Since that time he is DLR staff member and working on various aspects of SAR data processing and applications. He was the systems engineer for the Processing and Archiving Facility (PAF) for the X-SAR missions in 1996 and the project manager of the X-SAR data processing subsystem for the Shuttle Radar Topography Mission (SRTM) in 2000. Furthermore, he was the principal investigator for the SRTM along-track interferometry (ATI) experiments and pioneered the measurement of moving objects like cars and ocean currents from a spaceborne sensor. He worked on concepts for a close satellite formation flight for along-track interferometry. For six months he worked in the Toulouse space centre of CNES for the Cartwheel project and formed a joint DLR / CNES research team. He initiated the implementation of an ATI mode on TerraSAR-X and is currently the project manager of the "TerraSAR-X Traffic Monitoring Project".

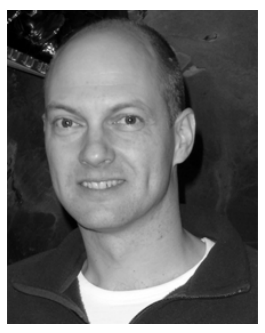

Steffen Suchandt received the Dipl.-Ing. degree in electrical engineering from the University of Rostock, Germany, in 1995. From 1996 to 1998 he worked in the field of biomedical engineering. Since 1998 he is a scientific employee at the Remote Sensing Technology Institute of DLR where he has been working on numerous aspects of interferometric SAR processing. He was engaged in data calibration, processor development, and digital elevation model processing of the Shuttle Radar Topography Mission (SRTM). His current work is focused on the design and development of an automatic traffic information extraction system for TerraSAR-X data. Further activities include research on inland river current measurements using airborne SAR. He has wide experience in SAR interferometry, ground moving target indication (GMTI), signal processing, and in software development.

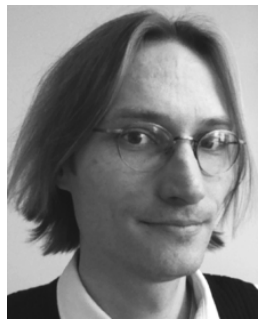

Ralph Kahle received the Dipl.-Ing. degree in aerospace engineering from the Technical University of Dresden, Germany, in 2001, and the Dr.-Ing. degree from the Technical University of Berlin, Germany, in 2005. He joined DLR's German Space Operations Center (GSOC) as a Flight Dynamics (FD) engineer in 2004. Dr. Kahle is responsible for the TerraSAR-X / TanDEM-X FD system engineering and operation. His field of work also comprises space mission analysis, FD software development, and conduction of Launch and Early Orbit Phase (LEOP) and routine FD operations.

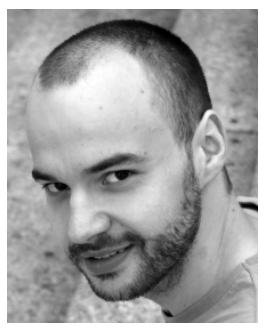

Cristian Rossi received the Laurea Magistrale (M.Sc.) degree in telecommunication engineering in 2006 from Politecnico di Milano, Italy, with a thesis on azimuth antenna pattern estimation from SAR data. From 2006 to 2008 he worked as project engineer in Aresys s.r.l. - a Politecnico di Milano spin-off company - being mainly involved in Sentinel-1 European Space Agency (ESA) projects. Since 2008, he is in the SAR Signal Processing department of the Earth Observation Center (EOC) at the German Aerospace Center (DLR), Oberpfaffenhofen, Germany, where he works on interferometric algorithms for the TanDEM-X mission. His current research interests focus on urban remote sensing, data fusion, and Doppler shift estimation for ocean currents.

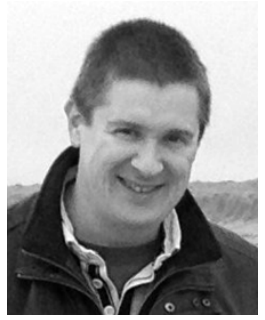

Paul S. Bell received an honours degree in Physics and Electronics in1992 from the School of Physics and Astronomy at the University of St Andrews, Scotland, and a Ph.D. in 2005 from the School of Ocean Sciences, University of Wales Bangor, with a dissertation on the remote determination of bathymetric changes using ground based radar. He has worked at the National Oceanography Centre, Liverpool (previously known as the Proudman Oceanographic Laboratory) since 1992, developing a variety of acoustic and radar techniques to study flow and sediment dynamics at coastal sites. He is currently working on the use of ground based remote sensing to map bathymetry, currents and other hydrodynamic properties at marine renewable energy sites. 


\section{TABLES}

TABLE 1

ACQUiSITION PARAMETERS / CONDITIONS OF THE THREE CONSIDERED TERRASAR-X / TANDEM-X ATI DATASETS

\begin{tabular}{|c|c|c|c|c|c|c|c|c|c|}
\hline $\begin{array}{c}\text { Data Acquisition } \\
\text { Time UTC }\end{array}$ & $\begin{array}{l}\text { Instrument } \\
\& \text { Mode }\end{array}$ & $\begin{array}{l}\text { Polari- } \\
\text { zation }\end{array}$ & $\begin{array}{c}\text { Look } \\
\text { Direction }\end{array}$ & $\begin{array}{c}\text { Effective } \\
\text { ATI Baseline }\end{array}$ & $\begin{array}{c}\text { ATI } \\
\text { Time Lag }\end{array}$ & $\begin{array}{l}\text { Incidence } \\
\text { Angle }\end{array}$ & $\begin{array}{l}\text { Velocity } \\
\text { Range }^{\mathrm{a}}\end{array}$ & $\begin{array}{l}\text { Wind } \\
\text { Speed }^{\mathrm{b}}\end{array}$ & $\begin{array}{c}\text { Wind } \\
\text { Direction }^{\mathrm{b}}\end{array}$ \\
\hline 2010-04-26 06:41 & TerraSAR-X DRA & $\mathrm{HH}$ & $286^{\circ}$ & $1.15 \mathrm{~m}$ & $0.15 \mathrm{~ms}$ & $29.7-32.6^{\circ}$ & $199.90 \mathrm{~m} / \mathrm{s}$ & $6.2 \mathrm{~m} / \mathrm{s}$ & $240^{\circ}$ \\
\hline $2012-02-2606: 41$ & TanDEM-X & VV & $286^{\circ}$ & $24.35-25.77 \mathrm{~m}$ & $3.17-3.36 \mathrm{~ms}$ & $29.8-32.8^{\circ}$ & $9.14 \mathrm{~m} / \mathrm{s}$ & $4.0 \mathrm{~m} / \mathrm{s}$ & $225^{\circ}$ \\
\hline 2012-03-19 06:41 & TanDEM-X & VV & $286^{\circ}$ & $39.48-40.90 \mathrm{~m}$ & $5.14-5.33 \mathrm{~ms}$ & $29.9-32.9^{\circ}$ & $5.69 \mathrm{~m} / \mathrm{s}$ & $5.1 \mathrm{~m} / \mathrm{s}$ & $190^{\circ}$ \\
\hline
\end{tabular}




\section{FIGURE CAPTIONS}

Fig. 1. Map showing the northern part of Scotland and the Orkney Islands north of it, with a white arrow pointing at the Pentland Firth. Source: Google Earth. The three TerraSAR-X / TanDEM-X datasets were acquired on descending overpasses with a heading of $196^{\circ}$ and a radar look direction of $286^{\circ}$.

Fig. 2. Data from the TerraSAR-X DRA mode overpass on April 26, 2010, 06:41 UTC, averaged over $25 \mathrm{~m} \times 25 \mathrm{~m}$ grid cells: (a) interferogram amplitude, (b) coherence, (c) phase converted into horizontal Doppler velocity. Shown area size $\approx 30 \mathrm{~km} \times 30 \mathrm{~km}$; radar look direction $=$ from right to left; positive velocity direction $=$ from left to right.

Fig. 3. Same as Fig. 2, but for TanDEM-X data from February 26 (top) and March 19, 2012 (bottom), both 06:41 UTC. The artifacts in the center of (f) illustrate the effect of phase wrapping at long baselines, which can be easily corrected in this case.

Fig. 4. Magnified subsections of Figs. 3a and c (February 26, 2012), showing wave signatures in the interferogram (a) amplitude and (b) phase converted into horizontal Doppler velocity. Here the full-resolution data were averaged over grid cells of $8.40 \mathrm{~m} \times 8.46 \mathrm{~m}(5 \times 4$ samples per grid cell $)$; shown area size $\approx 10 \mathrm{~km} \times 10 \mathrm{~km}$.

Fig. 5. Residual uncertainty (rms variability) of ATI-based line-of-sight Doppler velocities vs. number of averaged samples, as obtained from homogeneous $4096 \times 4096$ pixel subarrays of the full-resolution TerraSAR-X DRAmode interferogram from April 26, 2010 (solid line) and TanDEM-X interferogram from March 19, 2012 (dashed).

Fig. 6. Smoothed Doppler velocity (top) and corrected line-of-sight current fields (bottom) derived from the datasets of Figs. 2 and 3. Black frames outline the coverage of the DCA results of Fig. 11.

Fig. 7. Line-of-sight current fields in the test area from POLPRED for (a) April 26, 2010, (b) February 26, 2012, and (c) March 19, 2012, all 06:41 UTC.

Fig. 8. Differences between the ATI-based current fields of Fig. 6 and the POLPRED current fields of Fig. 7, averaged over each $1 \mathrm{~km} \times 1 \mathrm{~km}$ model grid cell. Red color indicates that the ATI-based current has a positive difference from the POLPRED current.

Fig. 9. Scatter diagrams of ATI-based vs. POLPRED currents and statistical analysis results for the three cases.

Fig. 10. Same as Fig. 9b, but using POLPRED current fields for later times (as indicated in boxes) that were found to agree better (case b) or about as well as the ones for 06:41 UTC (cases a, c) with the ATI-based current fields.

Fig. 11. Same as Fig. 6, but for DCA- instead of ATI-based Doppler velocity and current fields.

Fig. 12. Same as Fig. 8, but for differences between the DCA-based current fields of Fig. 11 and the POLPRED current fields.

Fig. 13. Same as Figs. 9 and 10 combined, but for DCA- instead of ATI-based currents vs. POLPRED currents.

Fig 14. Histograms of deviations of the ATI-based (thick line) and DCA-based (thin line) currents from the POLPRED currents, for the three considered cases (columns) and using POLPRED currents for 6:41 UTC (top row) and alternate times (bottom row). The height of each histogram bar shows the percentage of data points in the corresponding bin with a width of $0.25 \mathrm{~m} / \mathrm{s}$.

Fig. 15. Same as Figs. 8 and 12, but for differences between the DCA- and ATI-based Doppler velocity fields of Fig. 11 and 6 on a $25 \mathrm{~m} \times 25 \mathrm{~m}$ grid.

Fig. 16. Same as Fig. 9, but for DCA- vs. ATI-based Doppler velocities. 


\section{FIGURES}

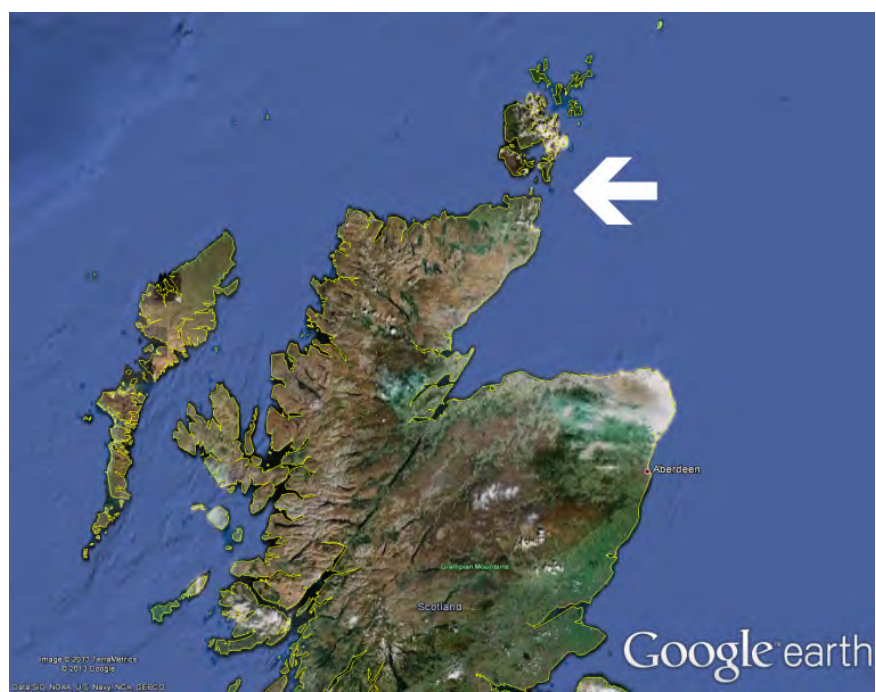

Fig. 1. Map showing the northern part of Scotland and the Orkney Islands north of it, with a white arrow pointing at the Pentland Firth. Source: Google Earth. The three TerraSAR-X / TanDEM-X datasets were acquired on descending overpasses with a heading of $196^{\circ}$ and a radar look direction of $286^{\circ}$. 


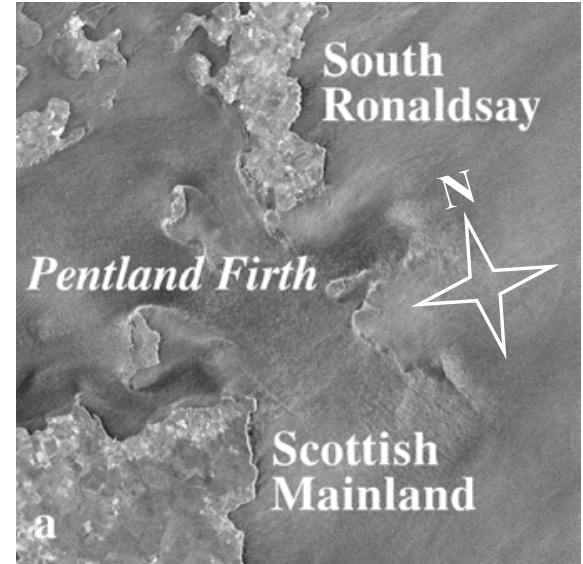

Interf Amp, Range $=20 \mathrm{~dB}$

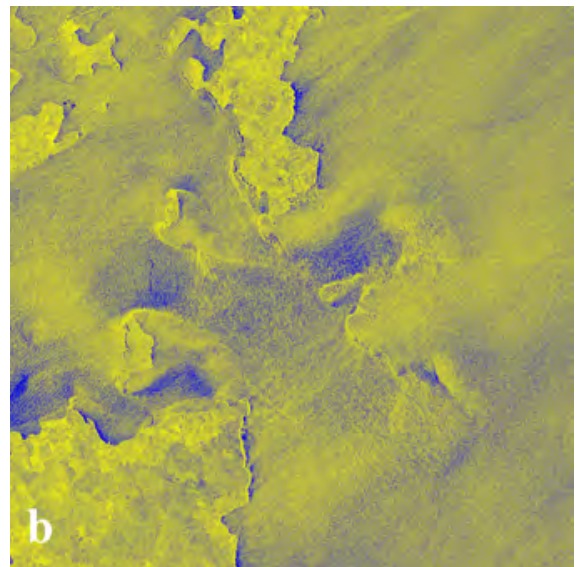

$0.0 \quad$ Coherence $\quad 1.0$
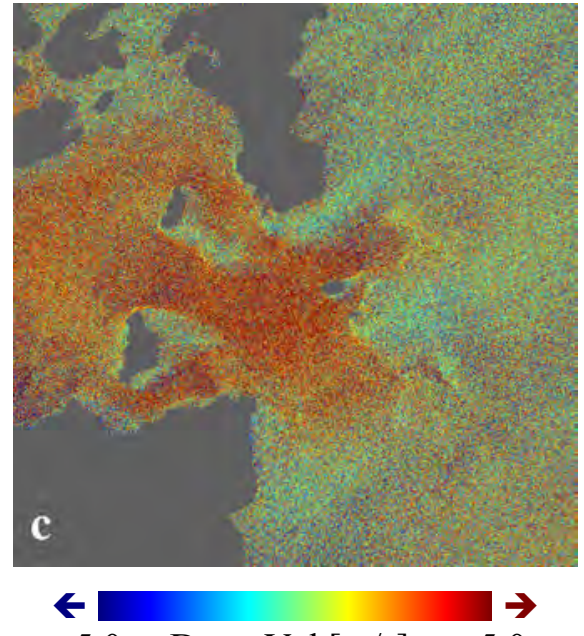

Fig. 2. Data from the TerraSAR-X DRA mode overpass on April 26, 2010, 06:41 UTC, averaged over $25 \mathrm{~m} \times 25 \mathrm{~m}$ grid cells: (a) interferogram amplitude, (b) coherence, (c) phase converted into horizontal Doppler velocity. Shown area size $\approx 30 \mathrm{~km} \times 30 \mathrm{~km}$; radar look direction $=$ from right to left; positive velocity direction = from left to right. 

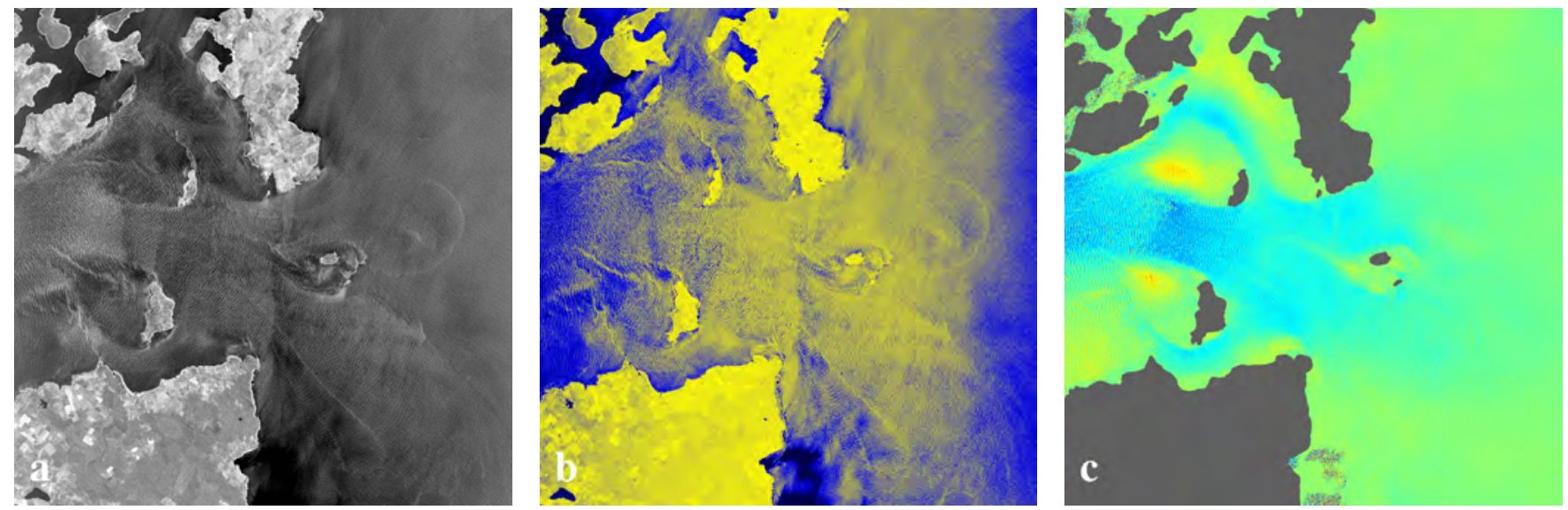

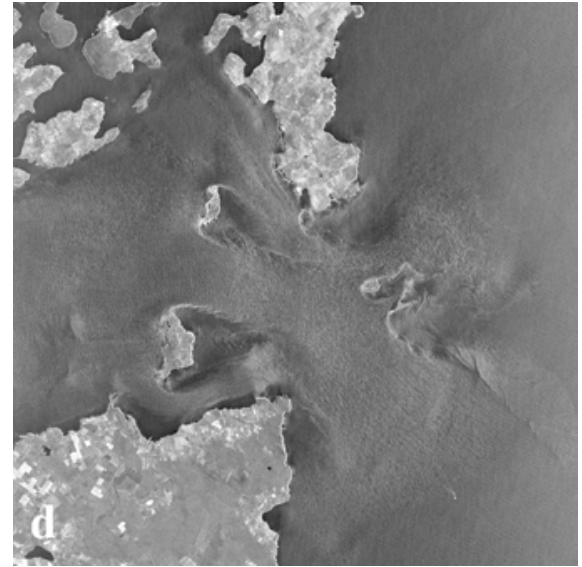

Interf Amp, Range $=20 \mathrm{~dB}$

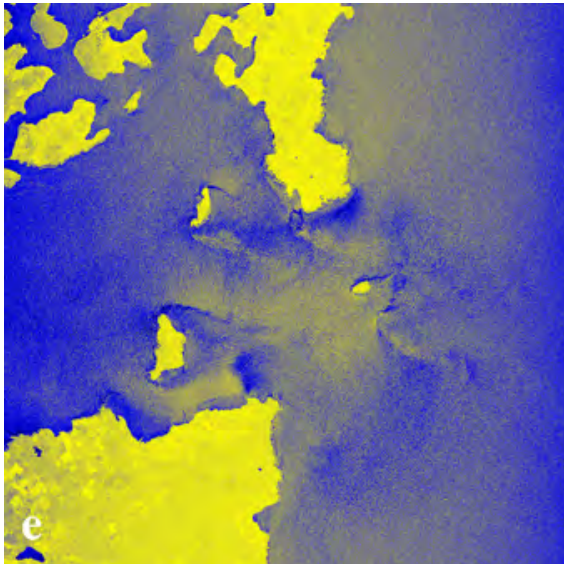

0.0 Coherence

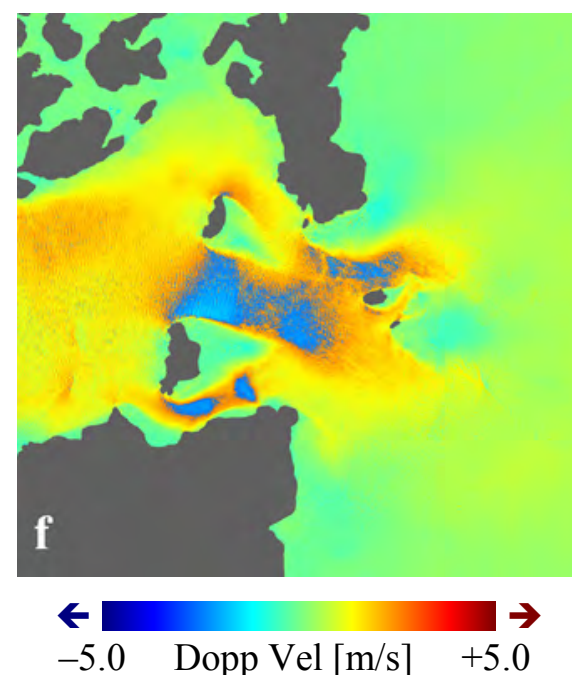

Fig. 3. Same as Fig. 2, but for TanDEM-X data from February 26 (top) and March 19, 2012 (bottom), both 06:41 UTC. The artifacts in the center of (f) illustrate the effect of phase wrapping at long baselines, which can be easily corrected in this case. 


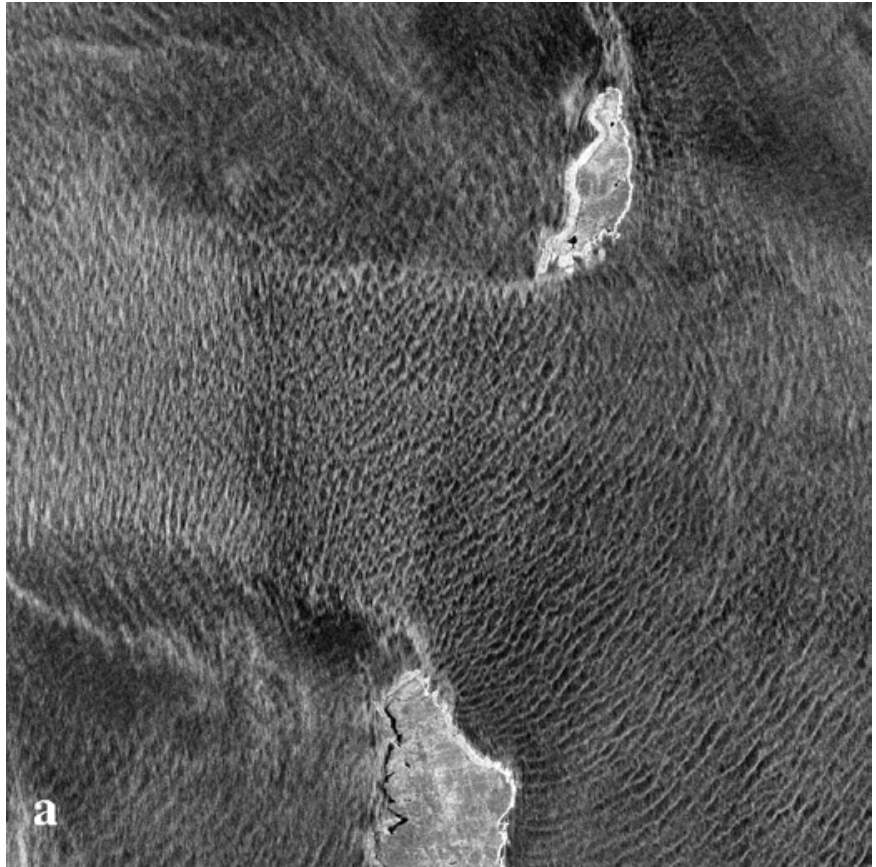

Interf Amp, Range $=20 \mathrm{~dB}$

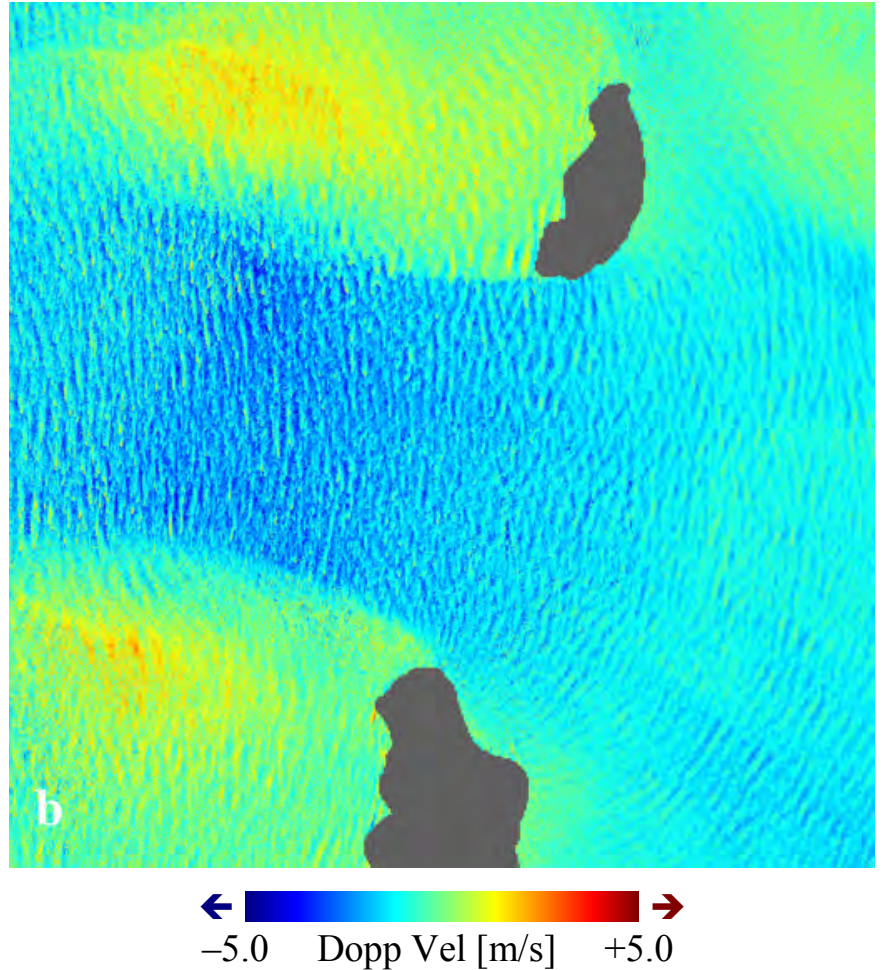

Fig. 4. Magnified subsections of Figs. 3a and c (February 26, 2012), showing wave signatures in the interferogram (a) amplitude and (b) phase converted into horizontal Doppler velocity. Here the full-resolution data were averaged over grid cells of $8.40 \mathrm{~m} \times 8.46 \mathrm{~m}(5 \times 4$ samples per grid cell $)$; shown area size $\approx 10 \mathrm{~km} \times 10 \mathrm{~km}$. 


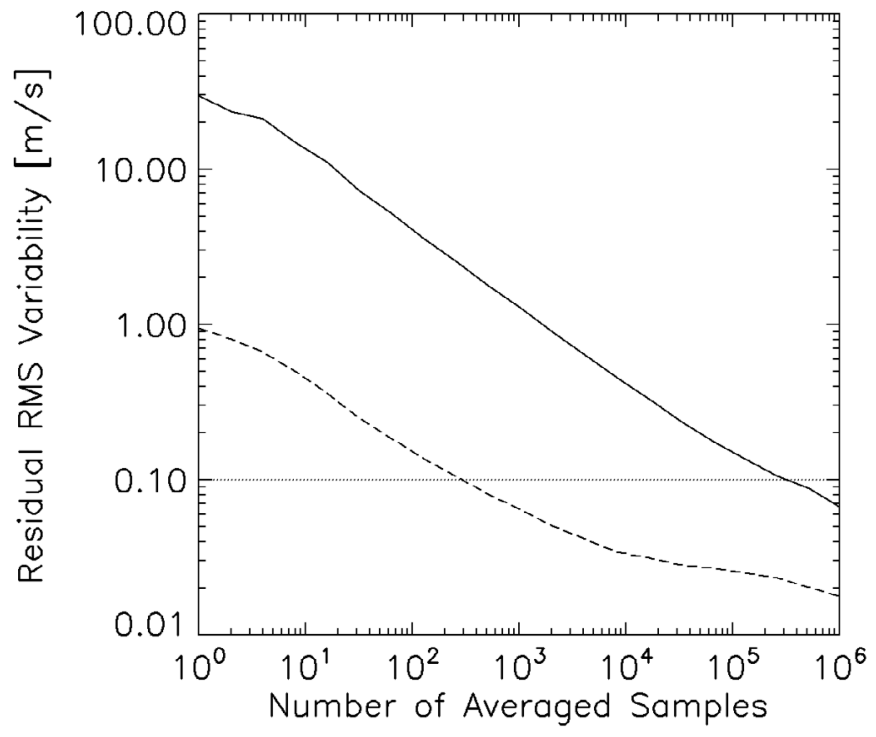

Fig. 5. Residual uncertainty (rms variability) of ATI-based line-of-sight Doppler velocities vs. number of averaged samples, as obtained from homogeneous $4096 \times 4096$ pixel subarrays of the full-resolution TerraSAR-X DRAmode interferogram from April 26, 2010 (solid line) and TanDEM-X interferogram from March 19, 2012 (dashed). 

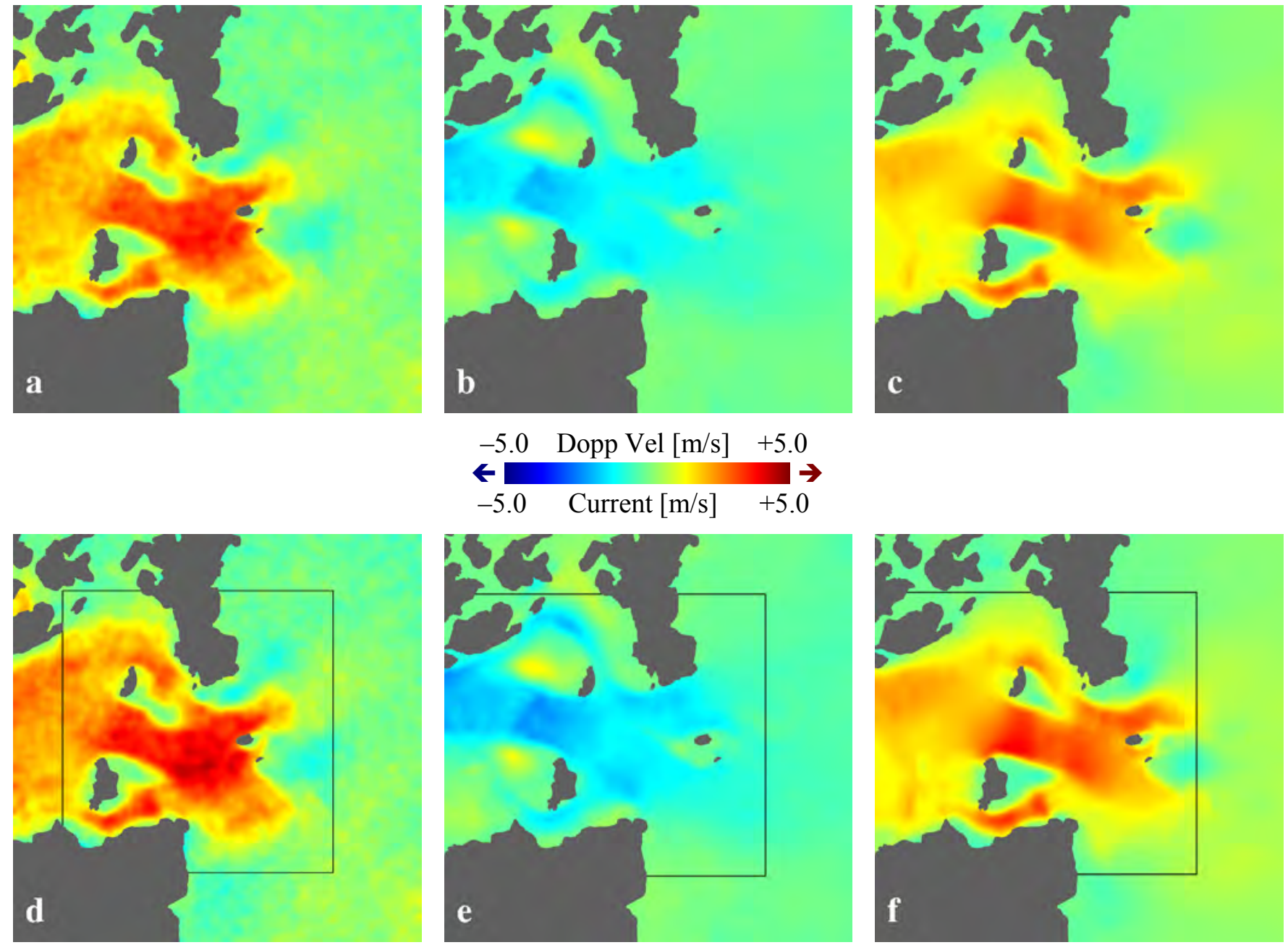

Fig. 6. Smoothed Doppler velocity (top) and corrected line-of-sight current fields (bottom) derived from the datasets of Figs. 2 and 3. Black frames outline the coverage of the DCA results of Fig. 11. 

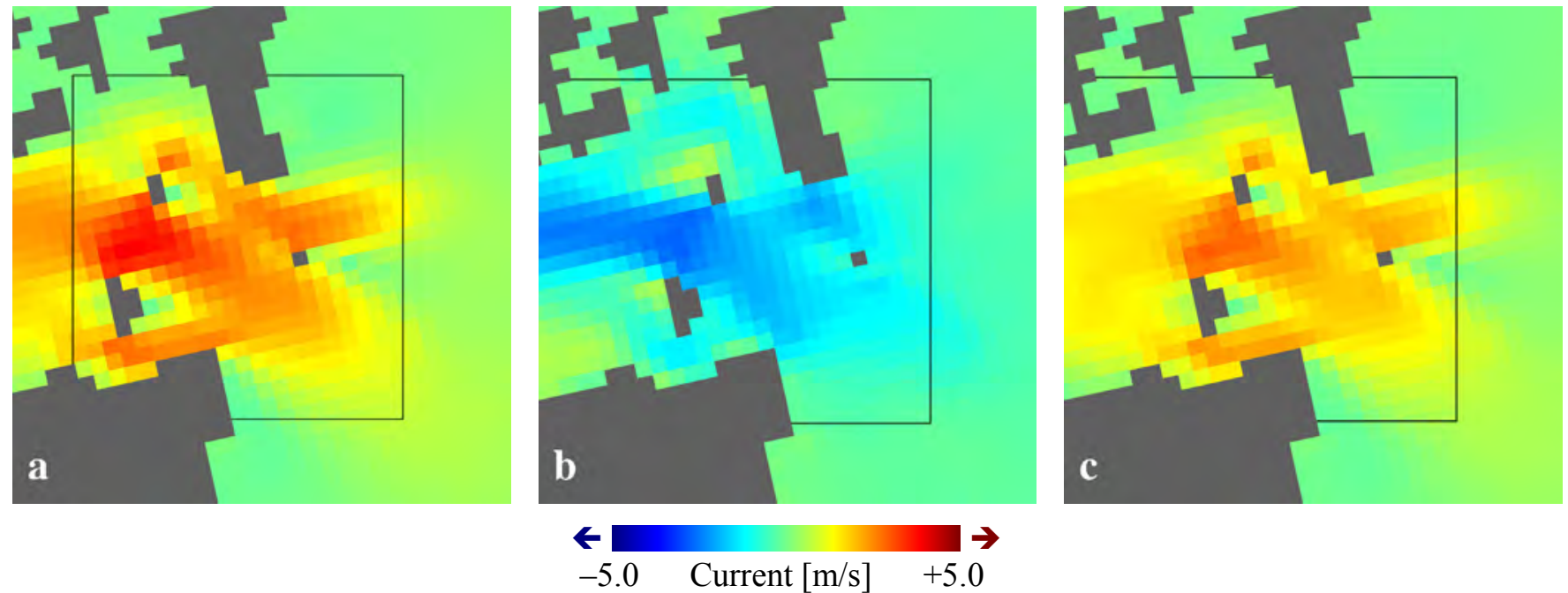

Fig. 7. Line-of-sight current fields in the test area from POLPRED for (a) April 26, 2010, (b) February 26, 2012, and (c) March 19, 2012, all 06:41 UTC. 

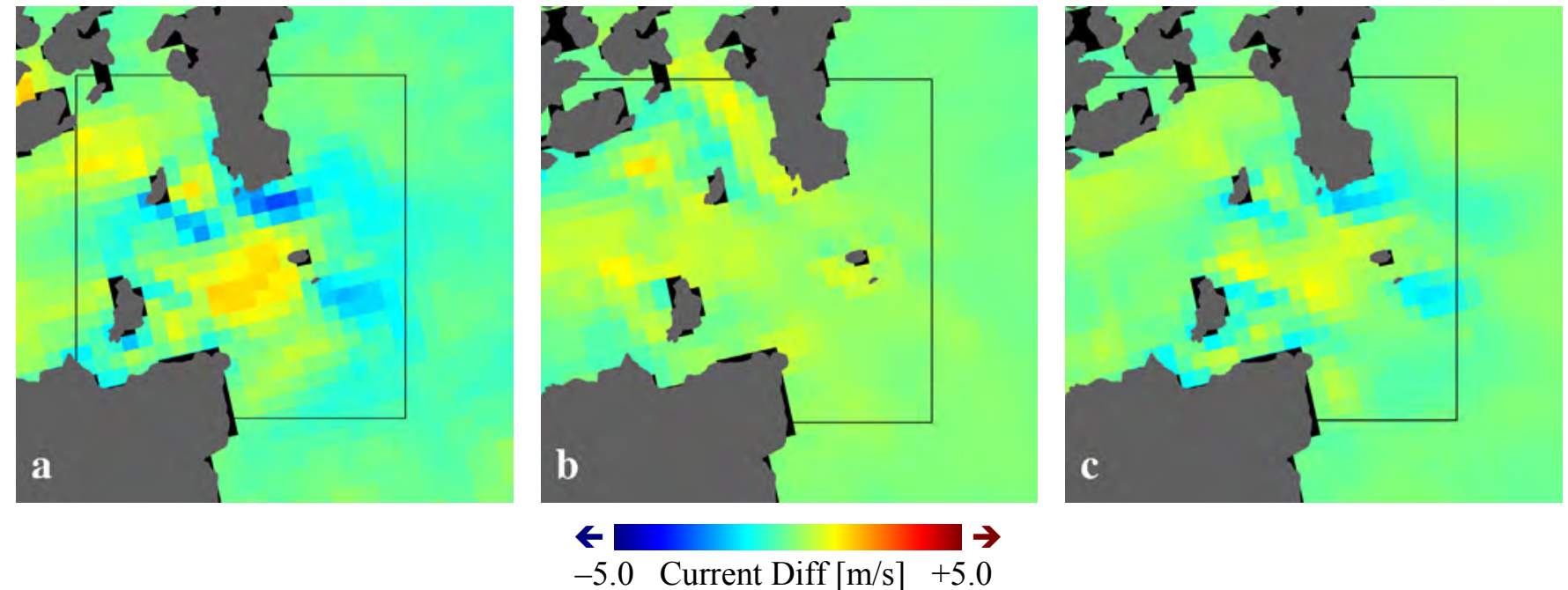

-5.0 Current Diff $[\mathrm{m} / \mathrm{s}]+5.0$

Fig. 8. Differences between the ATI-based current fields of Fig. 6 and the POLPRED current fields of Fig. 7, averaged over each $1 \mathrm{~km} \times 1 \mathrm{~km}$ model grid cell. Red color indicates that the ATI-based current has a positive difference from the POLPRED current. 

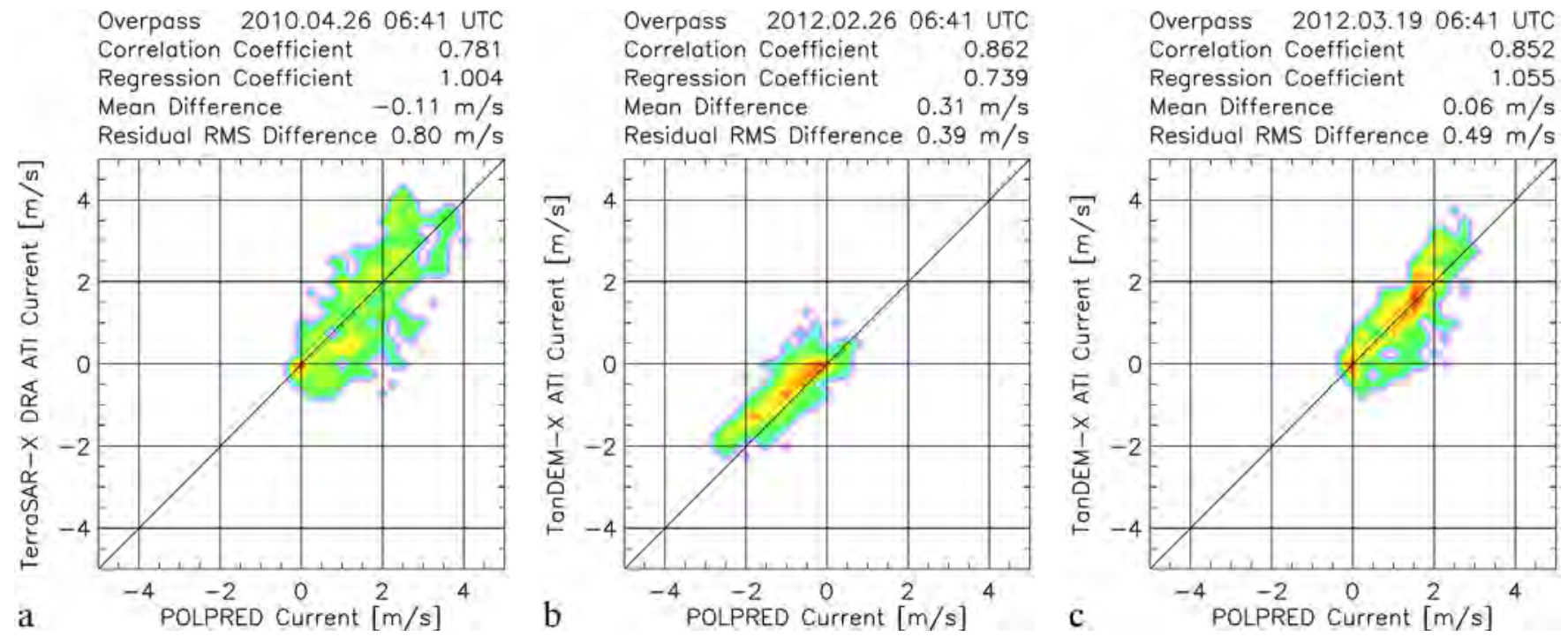

Fig. 9. Scatter diagrams of ATI-based vs. POLPRED currents and statistical analysis results for the three cases. 

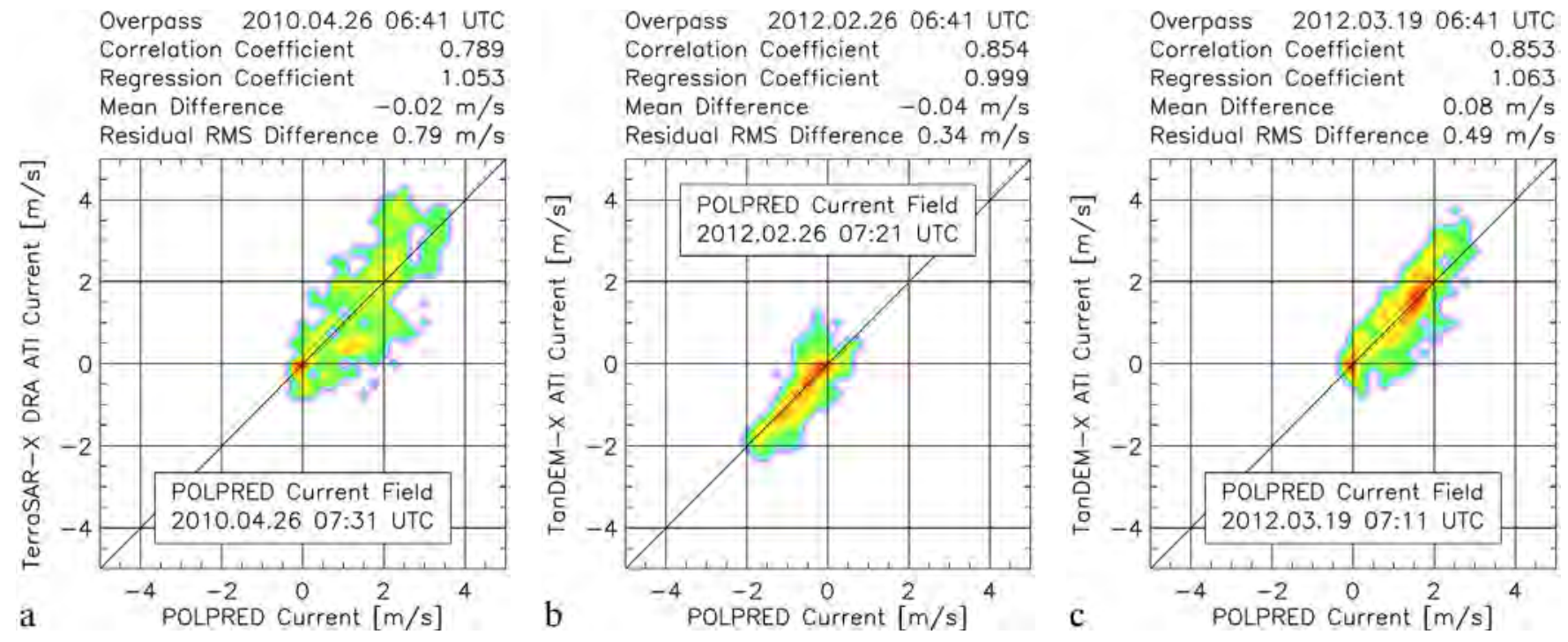

Fig. 10. Same as Fig. 9b, but using POLPRED current fields for later times (as indicated in boxes) that were found to agree better (case b) or about as well as the ones for 06:41 UTC (cases a, c) with the ATI-based current fields. 

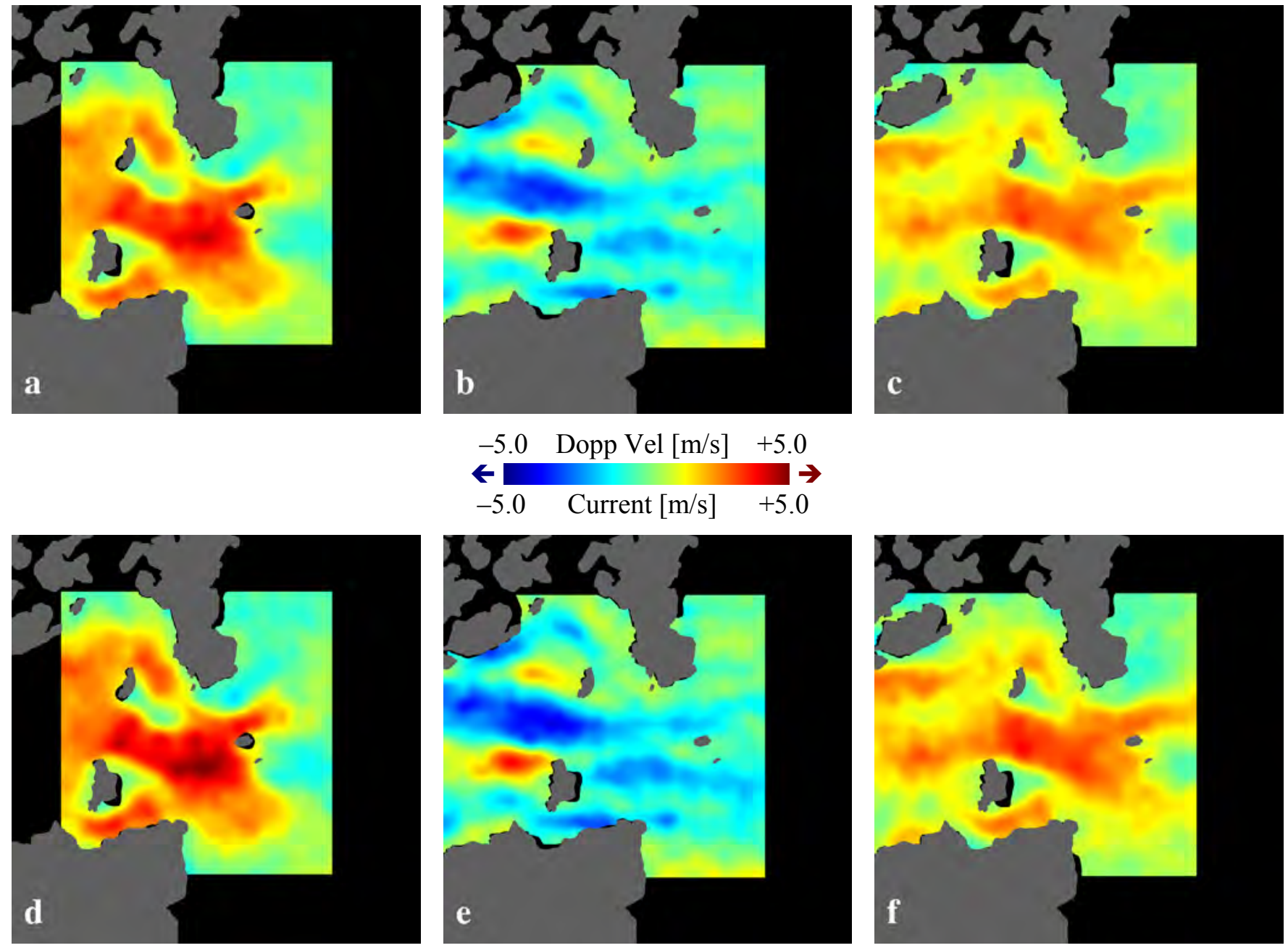

Fig. 11. Same as Fig. 6, but for DCA- instead of ATI-based Doppler velocity and current fields. 

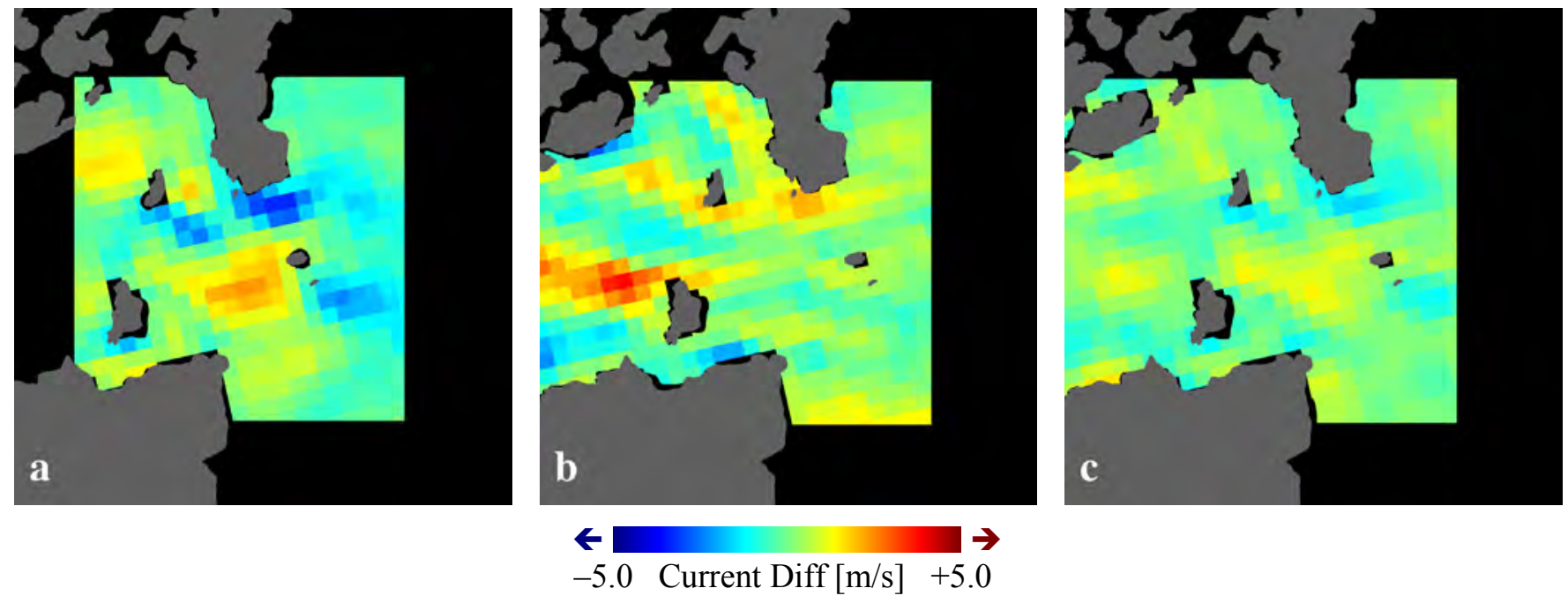

Fig. 12. Same as Fig. 8, but for differences between the DCA-based current fields of Fig. 11 and the POLPRED current fields. 

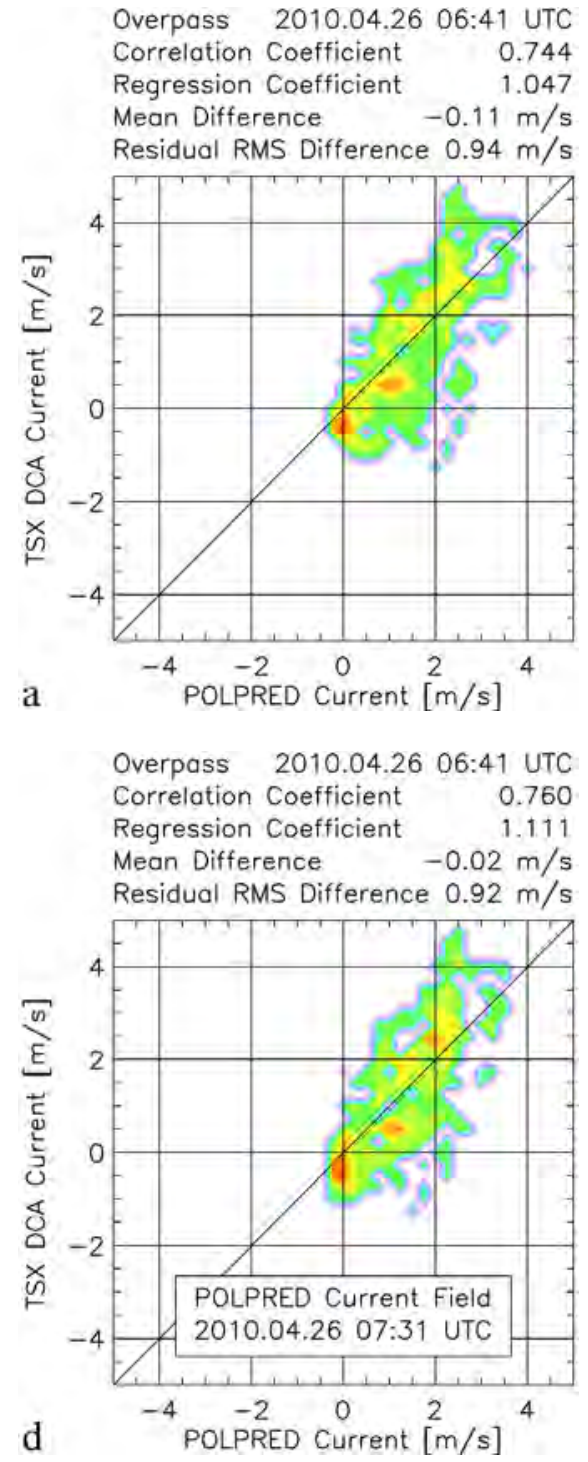

Overpass 2012.02.26 06:41 UTC Correlation Coefficient $\quad 0.638$ Regression Coefficient $\quad 0.937$ Mean Difference $0.32 \mathrm{~m} / \mathrm{s}$ Residual RMS Difference $0.86 \mathrm{~m} / \mathrm{s}$

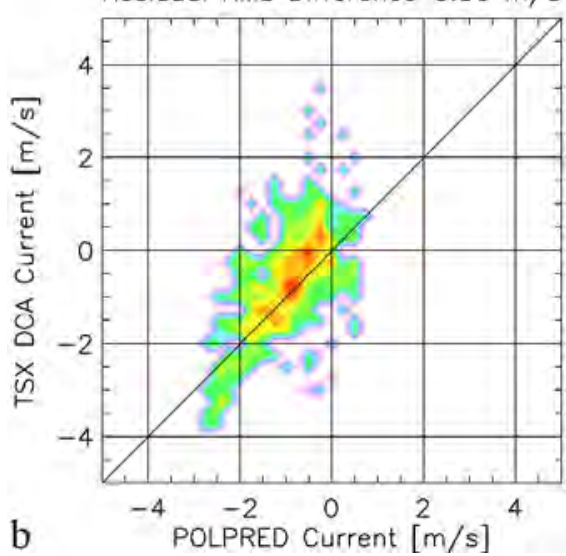

Overpass 2012.02.26 06:41 UTC Correlation Coefficient $\quad 0.626$ Regression Coefficient $\quad 1.248$ Mean Difference $\quad-0.04 \mathrm{~m} / \mathrm{s}$ Residual RMS Difference $0.88 \mathrm{~m} / \mathrm{s}$

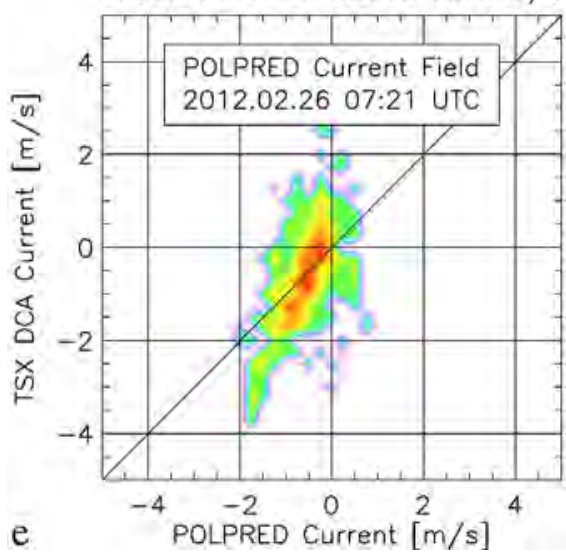

Overpass $\quad 2012.03 .19$ 06:41 UTC Correlation Coefficient 0.810 Regression Coefficient 0.995 Mean Difference $0.06 \mathrm{~m} / \mathrm{s}$

Residual RMS Difference $0.54 \mathrm{~m} / \mathrm{s}$

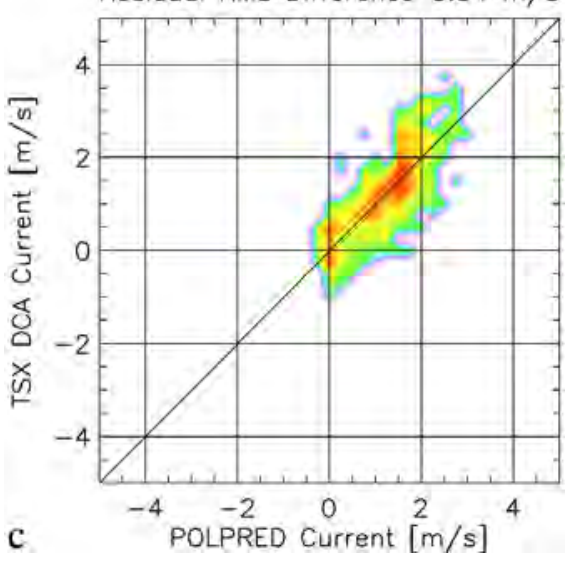

Overpass 2012.03.19 06:41 UTC Correlation Coefficient $\quad 0.816$ Regression Coefficient $\quad 1.009$ Mean Difference $\quad 0.08 \mathrm{~m} / \mathrm{s}$ Residual RMS Difference $0.54 \mathrm{~m} / \mathrm{s}$

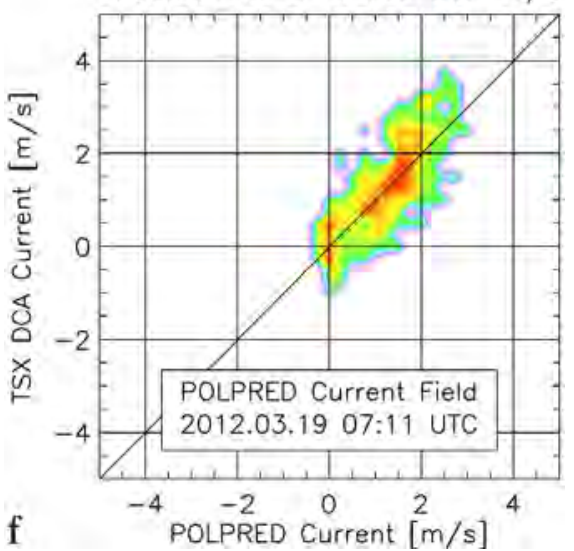

Fig. 13. Same as Figs. 9 and 10 combined, but for DCA- instead of ATI-based currents vs. POLPRED currents. 

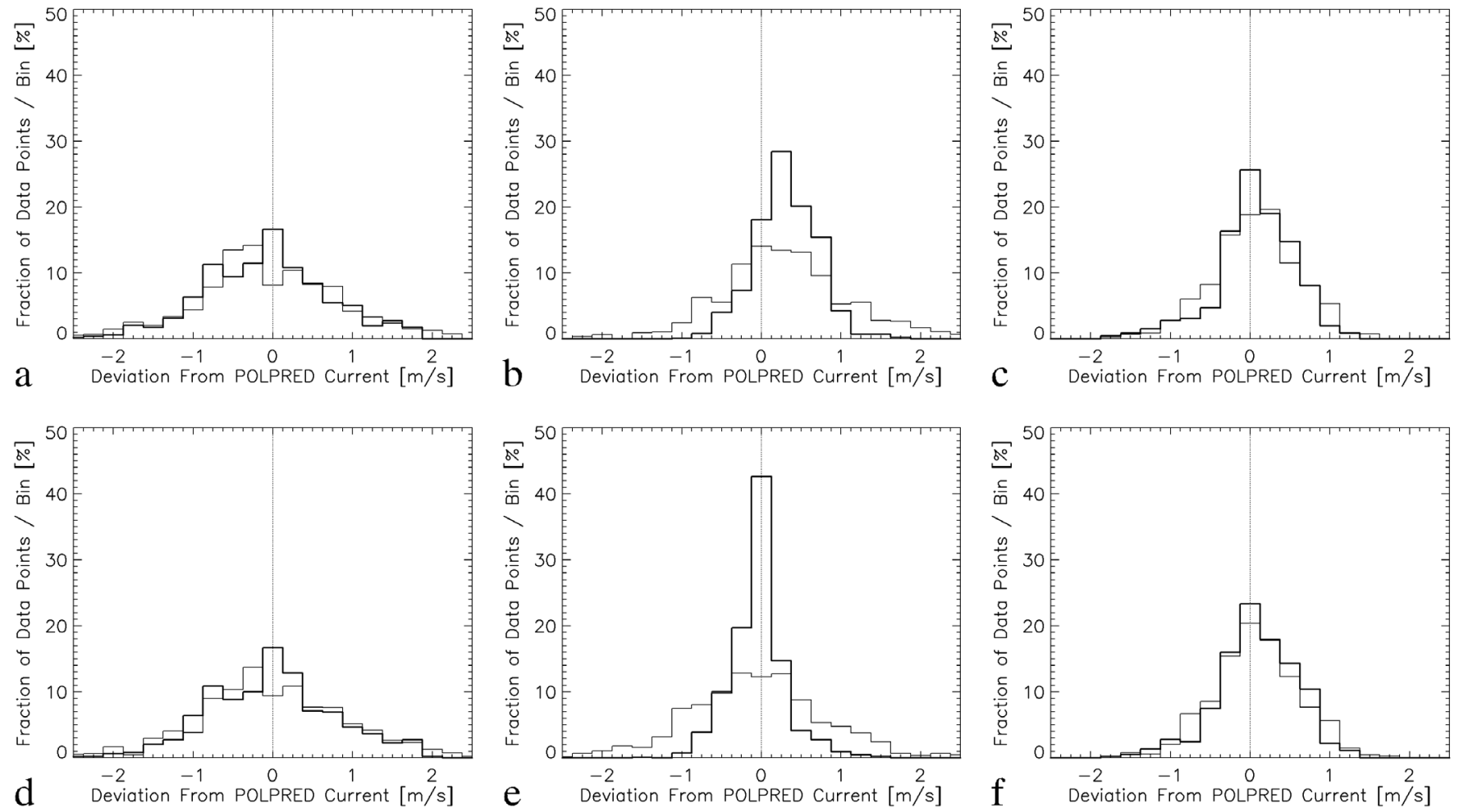

Fig 14. Histograms of deviations of the ATI-based (thick line) and DCA-based (thin line) currents from the POLPRED currents, for the three considered cases (columns) and using POLPRED currents for 6:41 UTC (top row) and alternate times (bottom row). The height of each histogram bar shows the percentage of data points in the corresponding bin with a width of $0.25 \mathrm{~m} / \mathrm{s}$. 

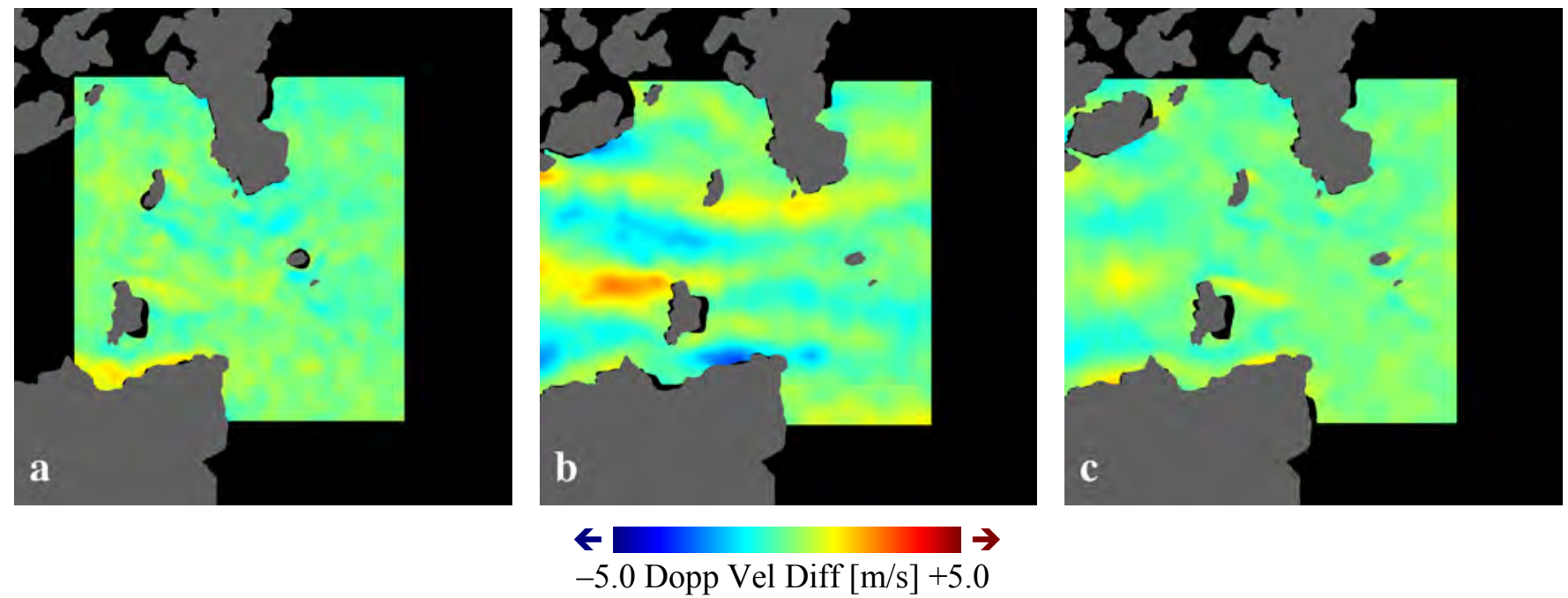

Fig. 15. Same as Figs. 8 and 12, but for differences between the DCA- and ATI-based Doppler velocity fields of Fig. 11 and 6 on a $25 \mathrm{~m} \times 25 \mathrm{~m}$ grid. 

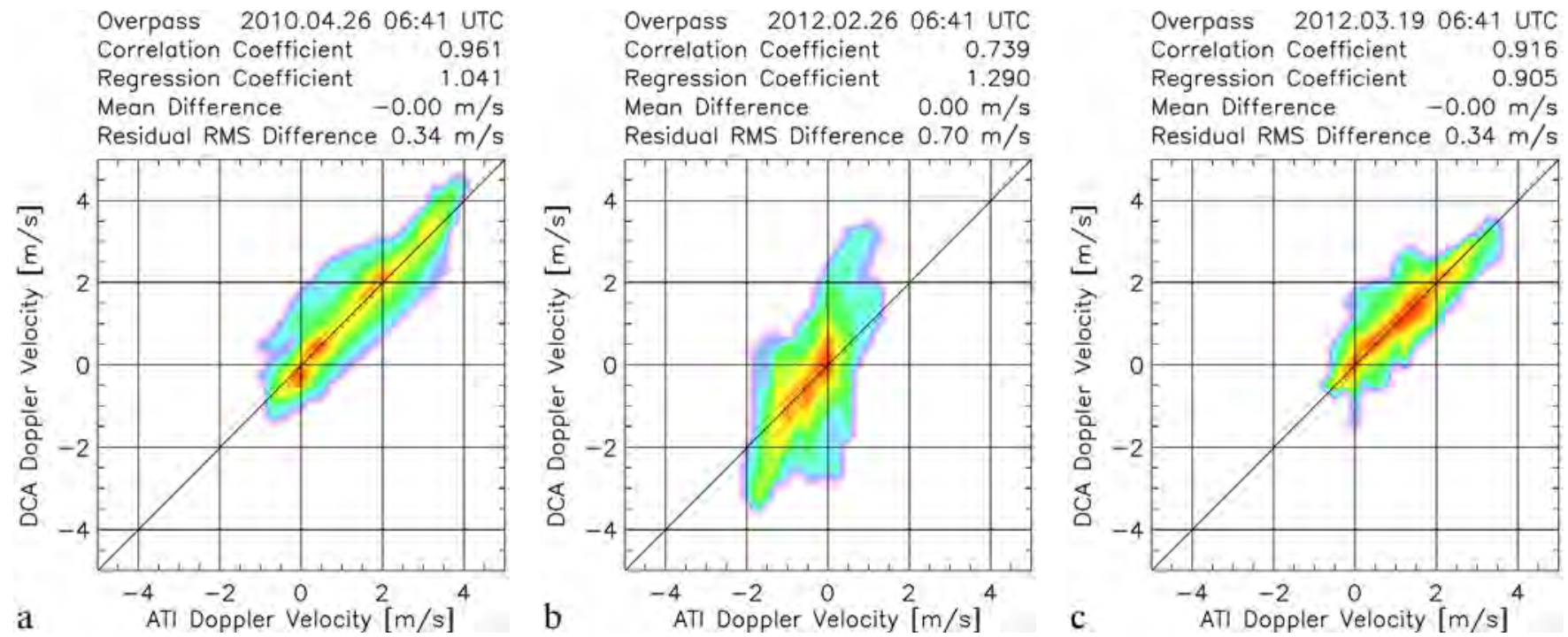

Fig. 16. Same as Fig. 9, but for DCA- vs. ATI-based Doppler velocities. 